\title{
Unusual Naphthoquinone Derivatives from the Twigs of
}

\author{
Avicennia marina \\ Li Han, ${ }^{\dagger, \ddagger}$ Xueshi Huang, ${ }^{\ddagger}$ Hans-Martin Dahse, ${ }^{\ddagger}$ Ute Moellmann,,${ }^{\ddagger}$ Hongzheng Fu, ${ }^{\dagger}$ Susanne Grabley, ${ }^{\ddagger}$ \\ Isabel Sattler, ${ }^{* *}$ Wenhan Lin, ${ }^{* \dagger}$, \\ State Key Laboratory of Natural and Biomimetic Drugs, Peking University, Beijing 100083, Peoples \\ Republic of China and Leibniz Institute for Natural Products Research and Infection Biology, Hans-Knöll- \\ Institute, Beutenbergstr. 11a, D-07745 Jena, Germany
}

Supplementary Material

*To whom correspondence should be addressed.

Tel: 0049-3641-656920. Fax: 0049-3641-656679. E-mail: isabel.sattler@hki-jena.de.

Tel: 0086-10-82806188. Fax: 0086-10-82802724. E-mail: whlin@bjmu.edu.cn.

${ }^{\dagger}$ Peking University.

* Hans-Knöll-Institute, Jena. 
Table of Contents

Fig. 1. ESI-MS spectrum of $\mathbf{1}$

page 3

Fig. 2. ${ }^{1} \mathrm{H}-\mathrm{NMR}$ spectrum of $\mathbf{1}$

page 3

Fig. 3. ${ }^{13} \mathrm{C}-\mathrm{NMR}$ spectrum of $1 \quad$ page 4

Fig. 4. DEPT spectrum of 1 page 4

Fig. 5. HMQC spectrum of 1 page 5

Fig. 6. HMBC spectrum of 1 page 5

Fig. 7. IR spectrum of 1 page 6

Fig. 8. $\mathrm{UV}\left(\mathrm{CH}_{3} \mathrm{OH}\right)$ spectrum of $\mathbf{1}$ page 6

Fig. 9. ESI-MS spectrum of 2 page 7

Fig. 10. ${ }^{1} \mathrm{H}$-NMR spectrum of 2 page 7

Fig. 11. ${ }^{13} \mathrm{C}$-NMR spectrum of 2 page 8

Fig. 12. DEPT spectrum of $\mathbf{2}$ page 8

Fig. 13. COSY spectrum of 2 page 9

Fig. 14. HMQC spectrum of 2 page 9

Fig. 15. HMBC spectrum of $\mathbf{2}$ page 10

Fig. 16. NOESY spectrum of $\mathbf{2}$ page 10

Fig. 17. IR spectrum of 2 page 11

Fig. 18. UV $\left(\mathrm{CH}_{3} \mathrm{OH}\right)$ spectrum of 2 page 11

Fig. 19. ESI-MS spectrum of $\mathbf{3}$ page 12

Fig. 20. ${ }^{1} \mathrm{H}$-NMR spectrum of 3 page 12

Fig. 21. ${ }^{13} \mathrm{C}$-NMR spectrum of 3 page 13

Fig. 22. DEPT spectrum of 3 page 13

Fig. 23. COSY spectrum of 3 page 14

Fig. 24. HMQC spectrum of 3 page 14

Fig. 25. HMBC spectrum of 3 page 15

Fig. 26. NOESY spectrum of 3 page 15

Fig. 27. IR spectrum of $3 \quad$ page 16

Fig. 28. UV $\left(\mathrm{CH}_{3} \mathrm{OH}\right)$ spectrum of 3 page 16

Fig. 29. CD spectrum of $3 \quad$ page 17

Fig. 30. ESI-MS spectrum of 4-5 page 17

Fig. 31. ${ }^{1} \mathrm{H}-\mathrm{NMR}$ spectrum of $\mathbf{4 - 5}$ page 18

Fig. 32. ${ }^{13} \mathrm{C}-\mathrm{NMR}$ spectrum of 4-5 page 18

Fig. 33. DEPT spectrum of 4-5 page 19

Fig. 34. COSY spectrum of 4-5 page 19

Fig. 35. HMQC spectrum of 4-5 page 20

Fig. 36. HMBC spectrum of 4-5 page 20

Fig. 37. NOESY spectrum of 4-5 page 21

Fig. 38. IR spectrum of 4-5 page 21

Fig. $39 \mathrm{UV}\left(\mathrm{CH}_{3} \mathrm{OH}\right)$ spectrum of 4-5 page 22

Fig. 40 ESI-MS spectrum of 6 page 22

Fig. $41{ }^{1}$ H-NMR spectrum of 6 page 23

Fig. $42{ }^{13} \mathrm{C}$-NMR spectrum of 6 page 23

Fig. 43 DEPT spectrum of $6 \quad$ page 24

Fig. 44 COSY spectrum of $6 \quad$ page 24

Fig. 45 HMQC spectrum of 6 page 25

Fig. 46 HMBC spectrum of 6 page 25

Fig. 47 NOESY spectrum of 6 page 26

Fig. 48 IR spectrum of $6 \quad$ page 26

Fig. $49 \mathrm{UV}\left(\mathrm{CH}_{3} \mathrm{OH}\right)$ spectrum of $6 \quad$ page 27

Fig. 50 ESI-MS spectrum of 7 page 27

Fig. 51 H-NMR spectrum of 7 page 28

Fig. $52{ }^{13}$ C-NMR spectrum of 7 page 28

Fig. 53 DEPT spectrum of 7 page 29

Fig. 54 COSY spectrum of 7 page 29

Fig. 55 HMQC spectrum of 7 page 30

Fig. 56 HMBC spectrum of $7 \quad$ page 30

Fig. 57 NOESY spectrum of 7 page 31

Fig. 58 IR spectrum of 7 page 31

Fig. $59 \mathrm{UV}\left(\mathrm{CH}_{3} \mathrm{OH}\right)$ spectrum of 7 page 32 
D:Latato3062706Han

27-Jun-03 10:55:22

$\mathrm{CHaO} 09$

O3062706Han \#1 10-117 RT: $2.86-2.97$ AV: 8 NL: $4.85 E 7$
$T:+c$ sid $=20.00$ Full ms [ $50.00-100000]$
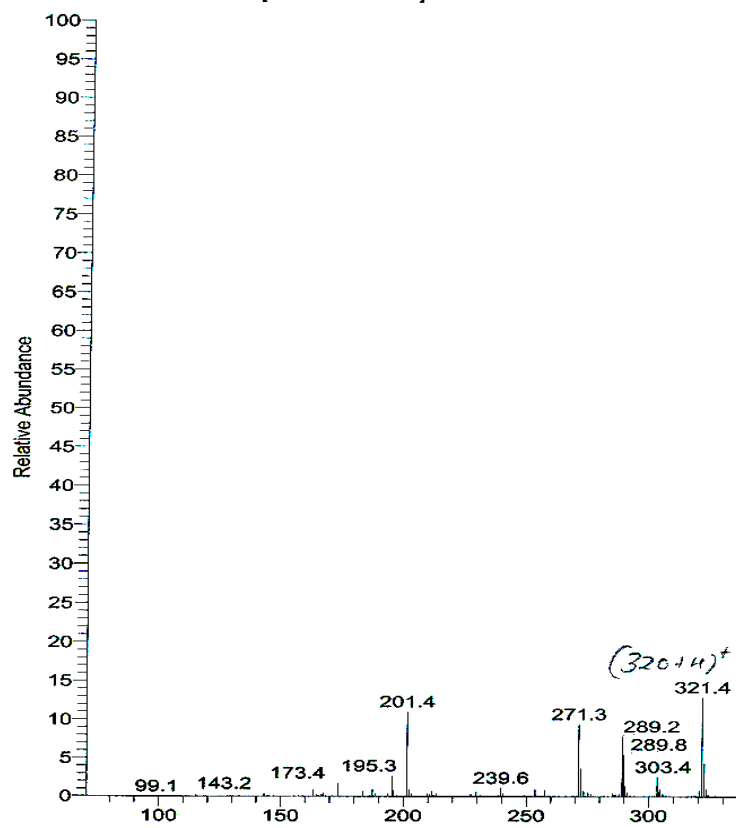

343.2

$(320+10)^{2}$

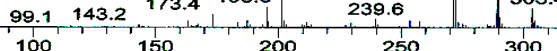

350

Fig. 1. ESI-MS spectrum of $\mathbf{1}$
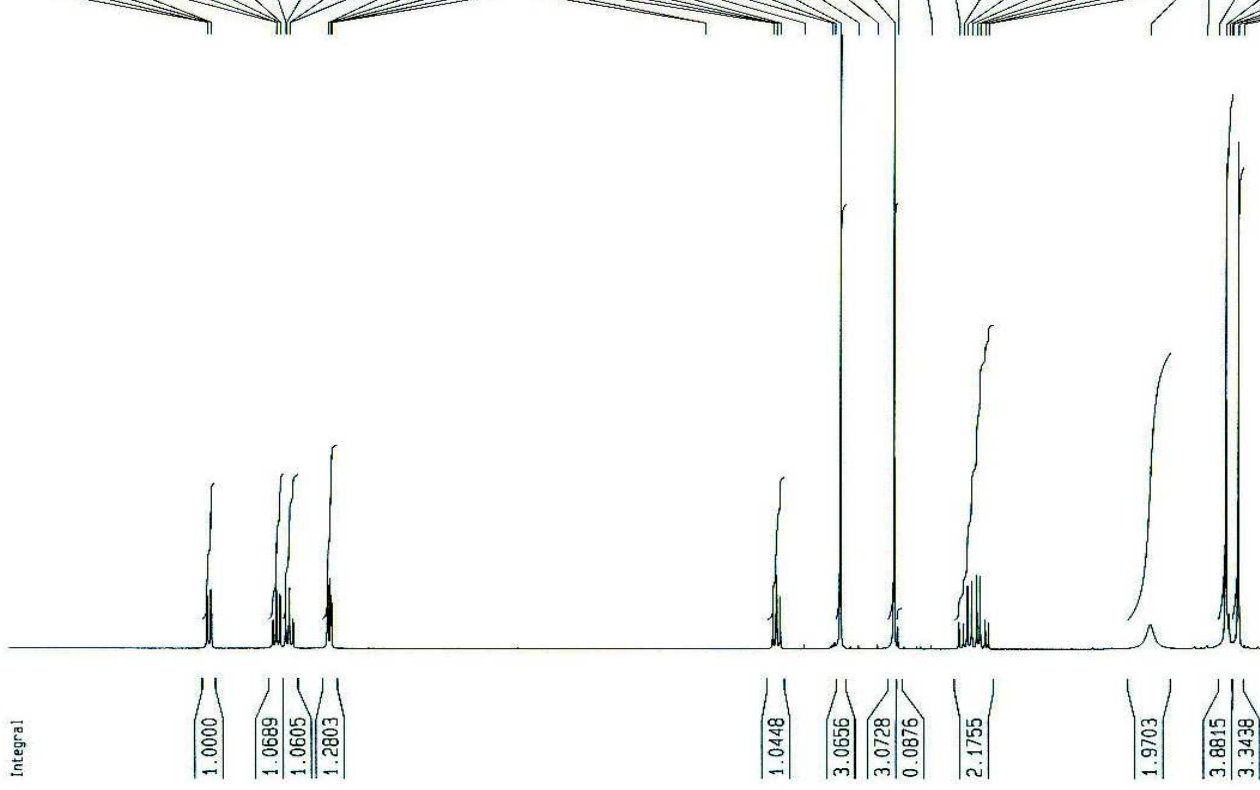

pom
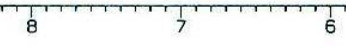

${ }_{3}^{1}$

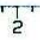

Fig. $2 .{ }^{1} \mathrm{H}-\mathrm{NMR}$ spectrum of $\mathbf{1}$ 


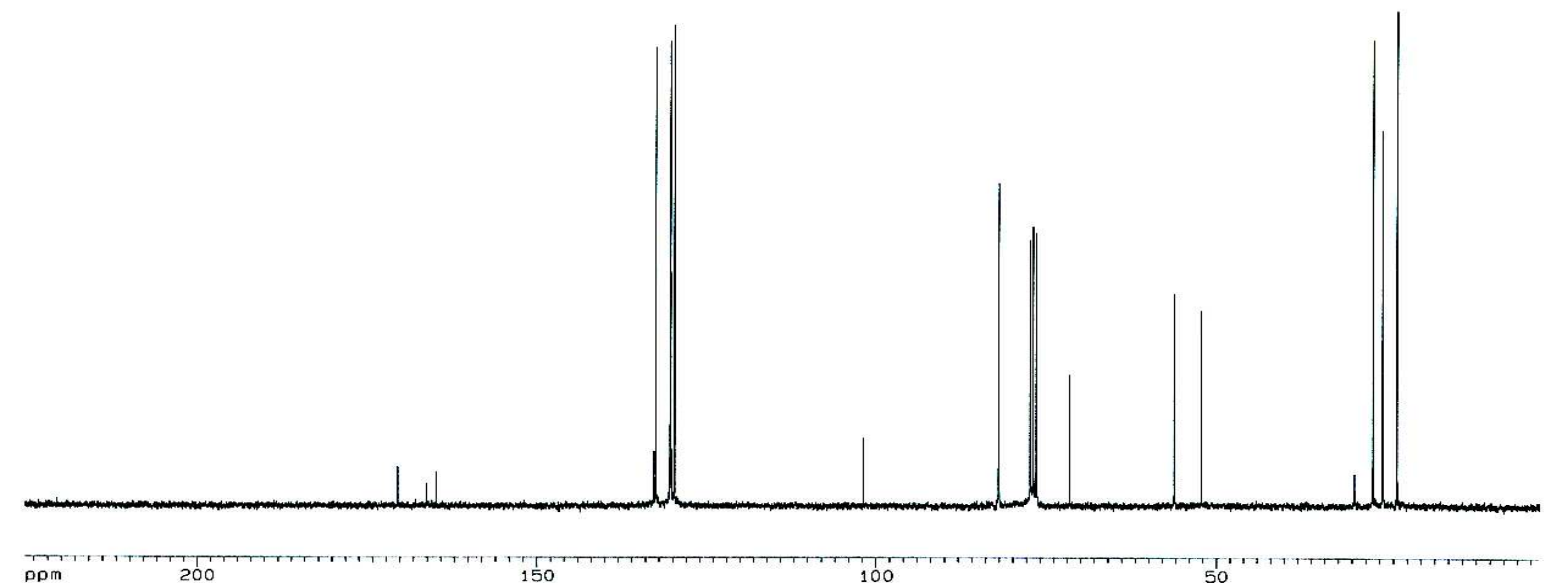

Fig. $3 .{ }^{13} \mathrm{C}-\mathrm{NMR}$ spectrum of $\mathbf{1}$
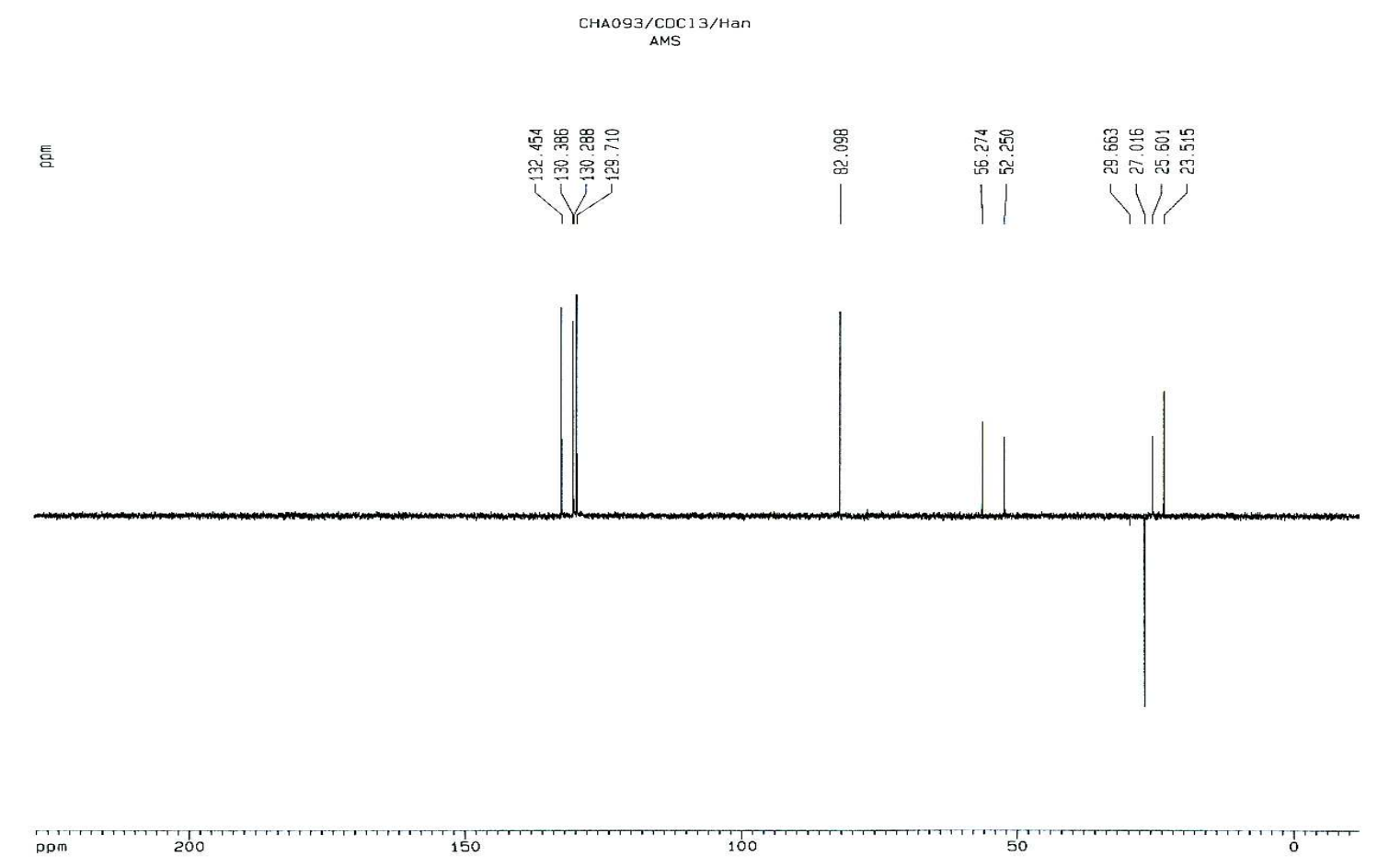

Fig. 4. DEPT spectrum of $\mathbf{1}$ 


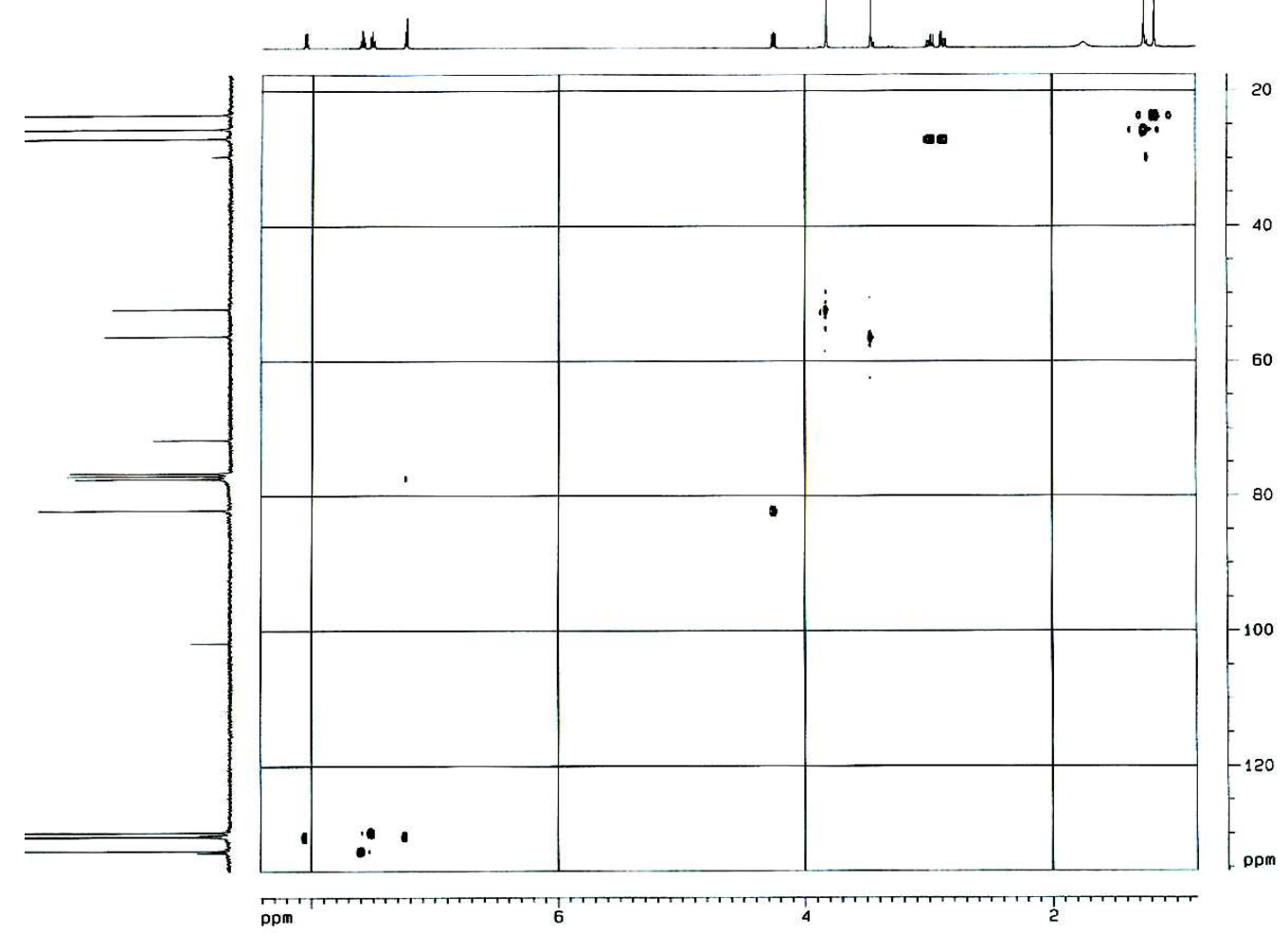

Fig. 5. HMQC spectrum of 1

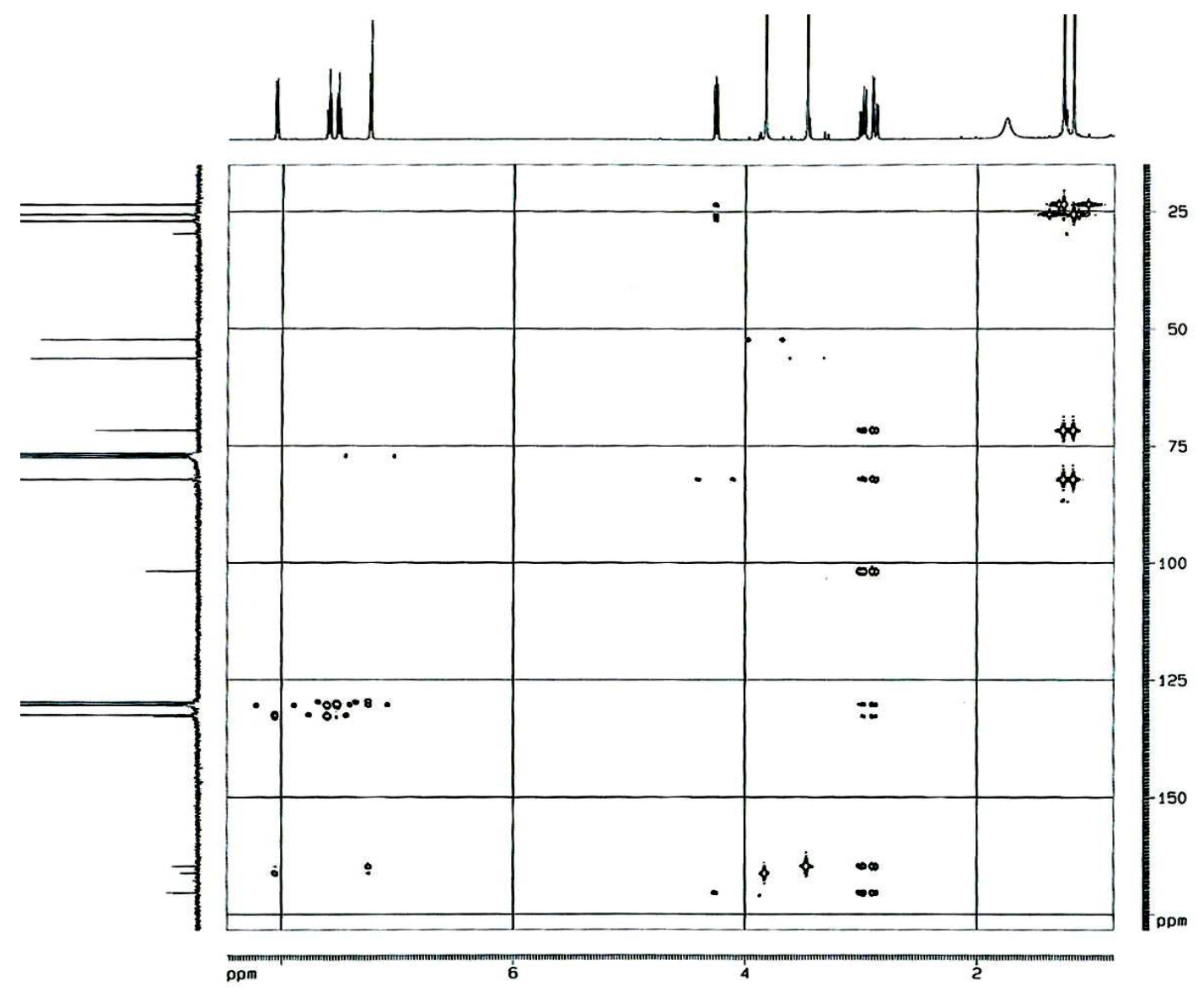

Fig. 6. HMBC spectrum of $\mathbf{1}$ 


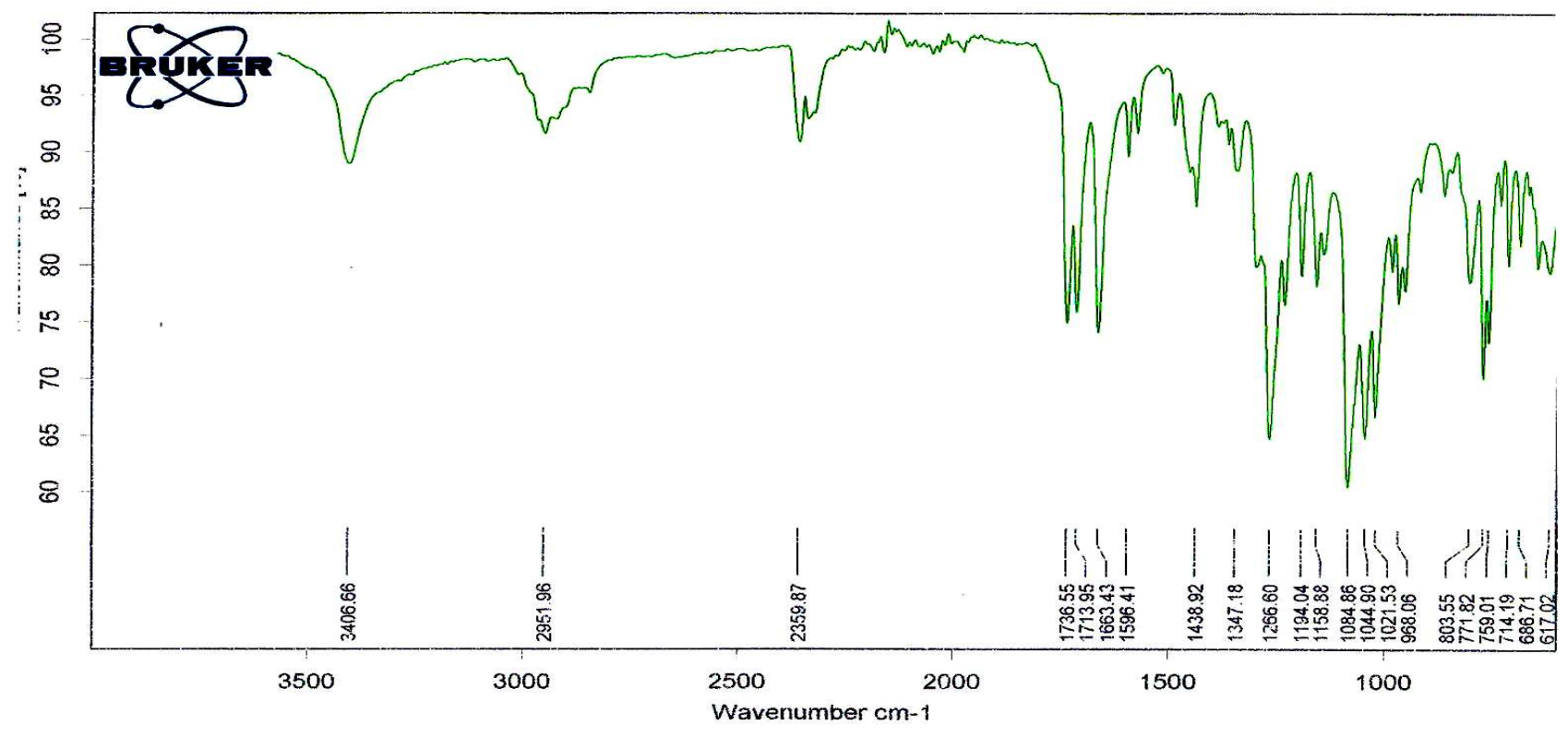

Fig. 7. IR spectrum of $\mathbf{1}$

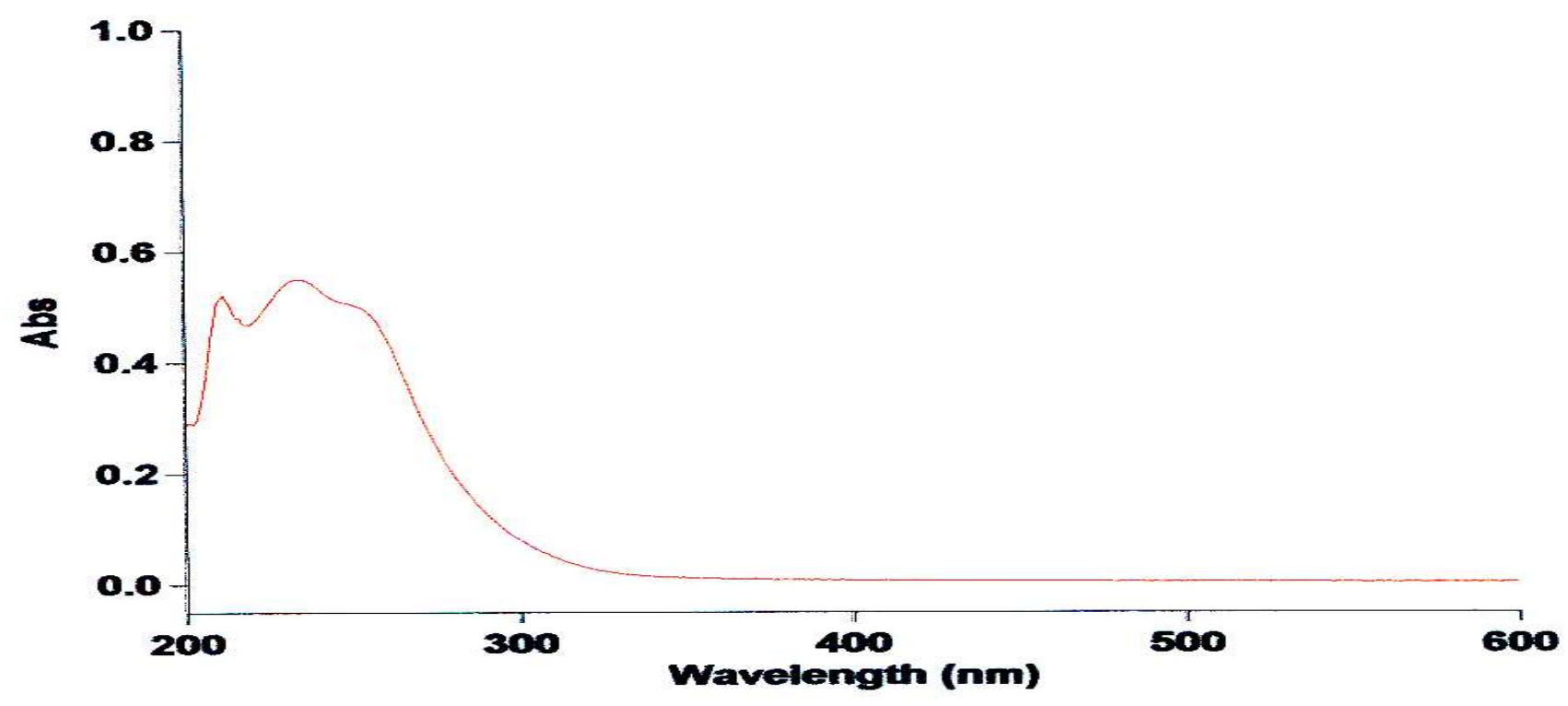

Fig. 8. UV $\left(\mathrm{CH}_{3} \mathrm{OH}\right)$ spectrum of $\mathbf{1}$ 


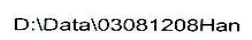

12-Aug-03 10:43:49

03081208Han \#39-40 RT: $1.07-1.09$ AV: 2 NL: $5.47 E 7$
T: $+c$ sid=20.00 Full ms [50.00-2000.00]

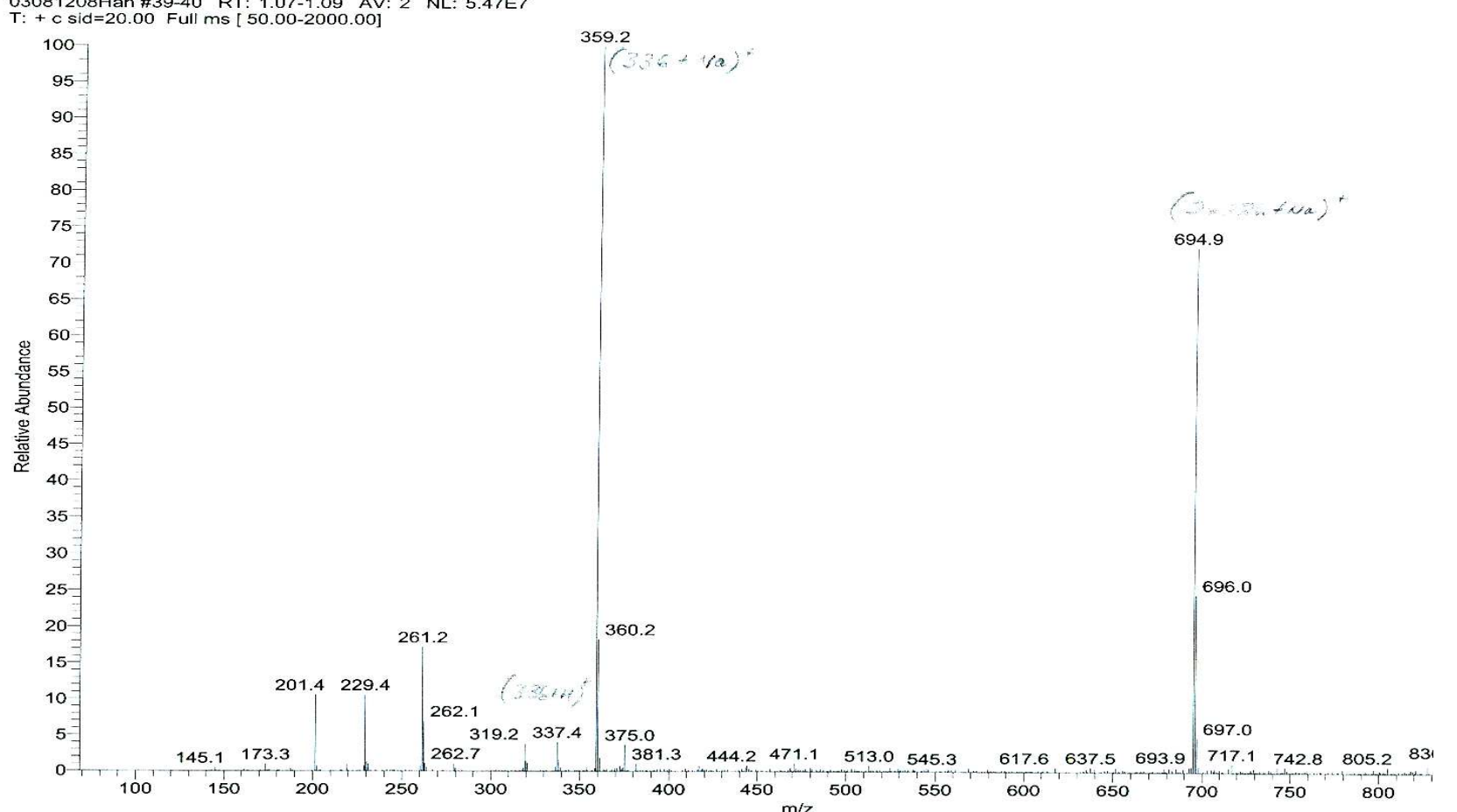

Fig. 9. ESI-MS spectrum of 2

CHA $108 / C D 300 / H a O / 1 H$

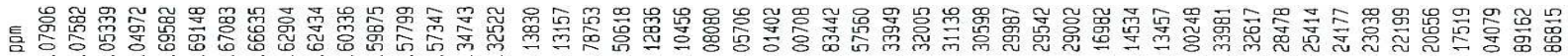

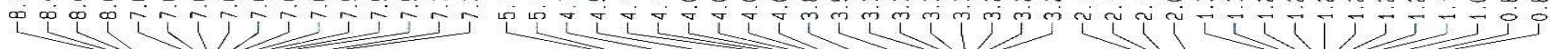

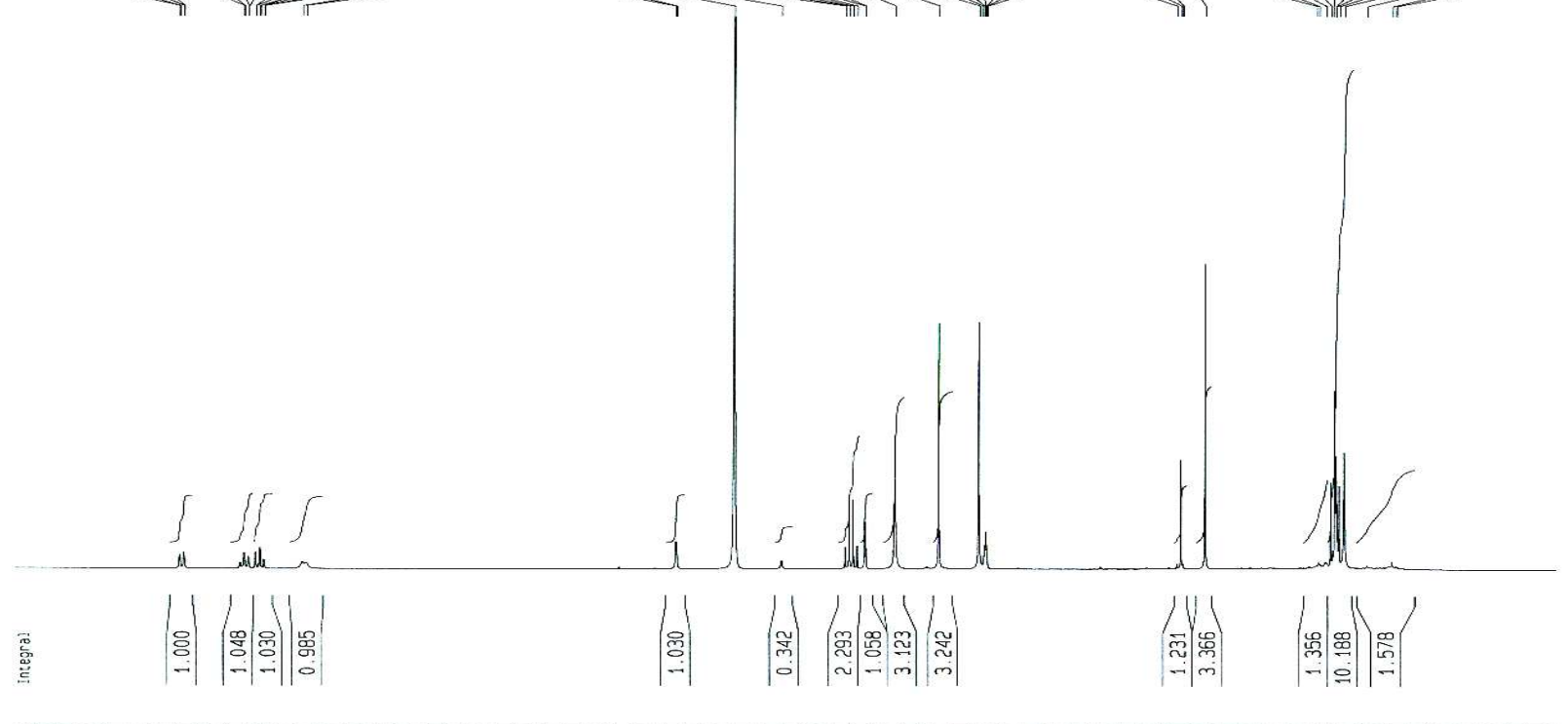

ppm

Fig. 10. ${ }^{1} \mathrm{H}-\mathrm{NMR}$ spectrum of 2 

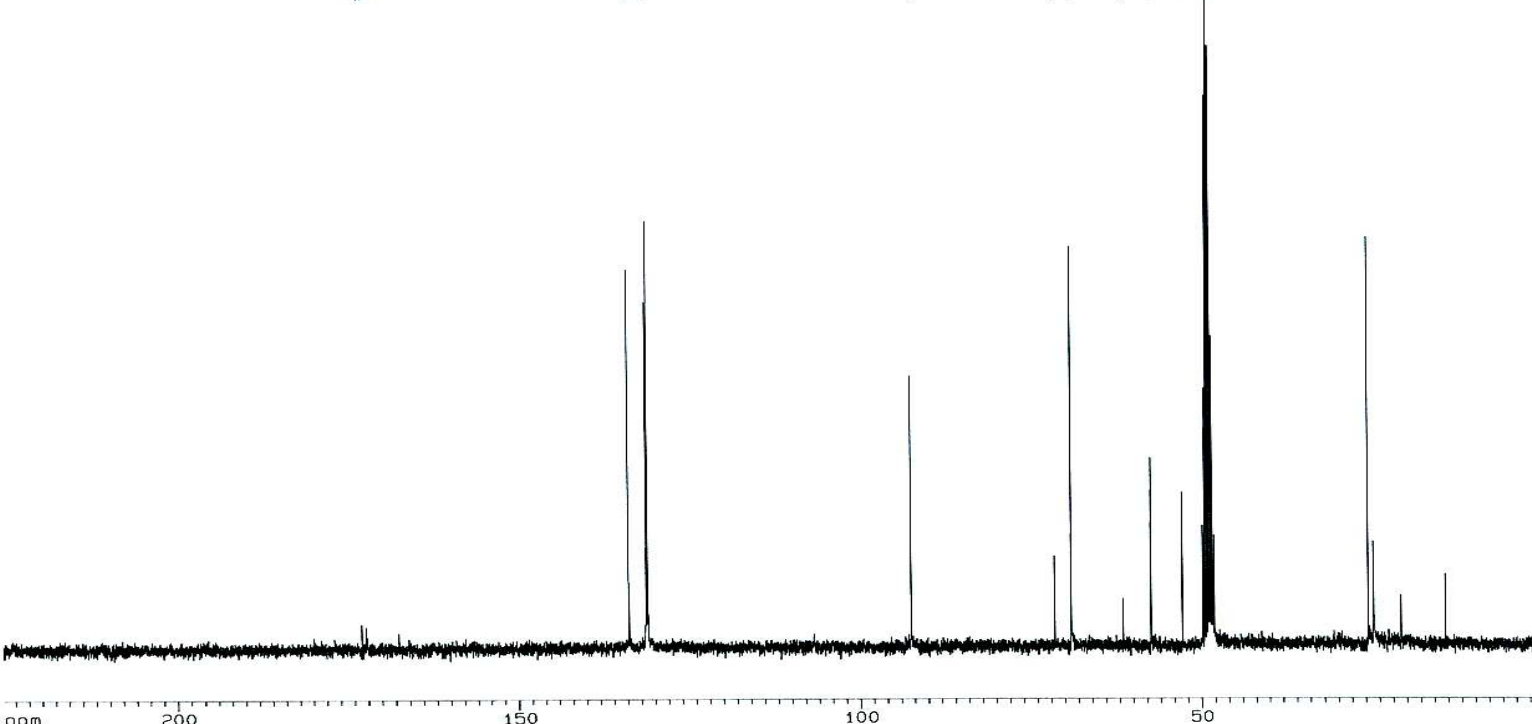

100

Fig. $11 .{ }^{13} \mathrm{C}-\mathrm{NMR}$ spectrum of $\mathbf{2}$

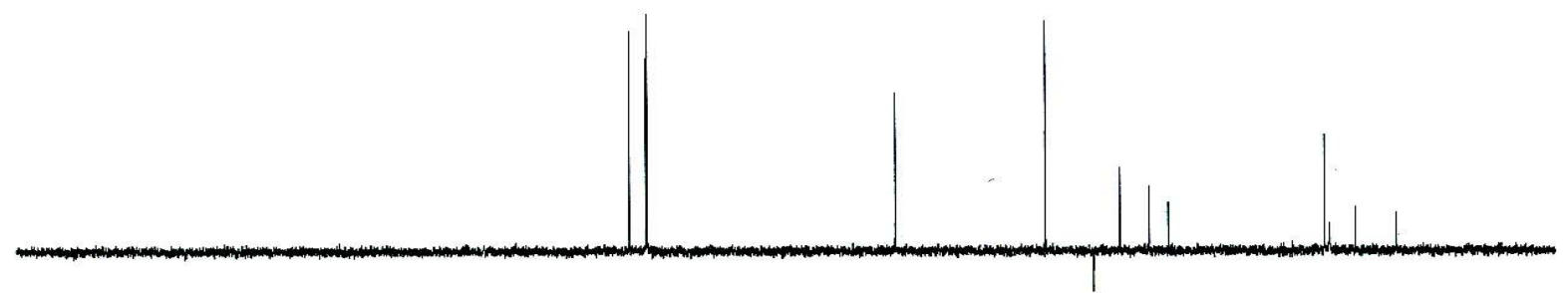

$$
\text { pom }
$$

Fig. 12. DEPT spectrum of 2 


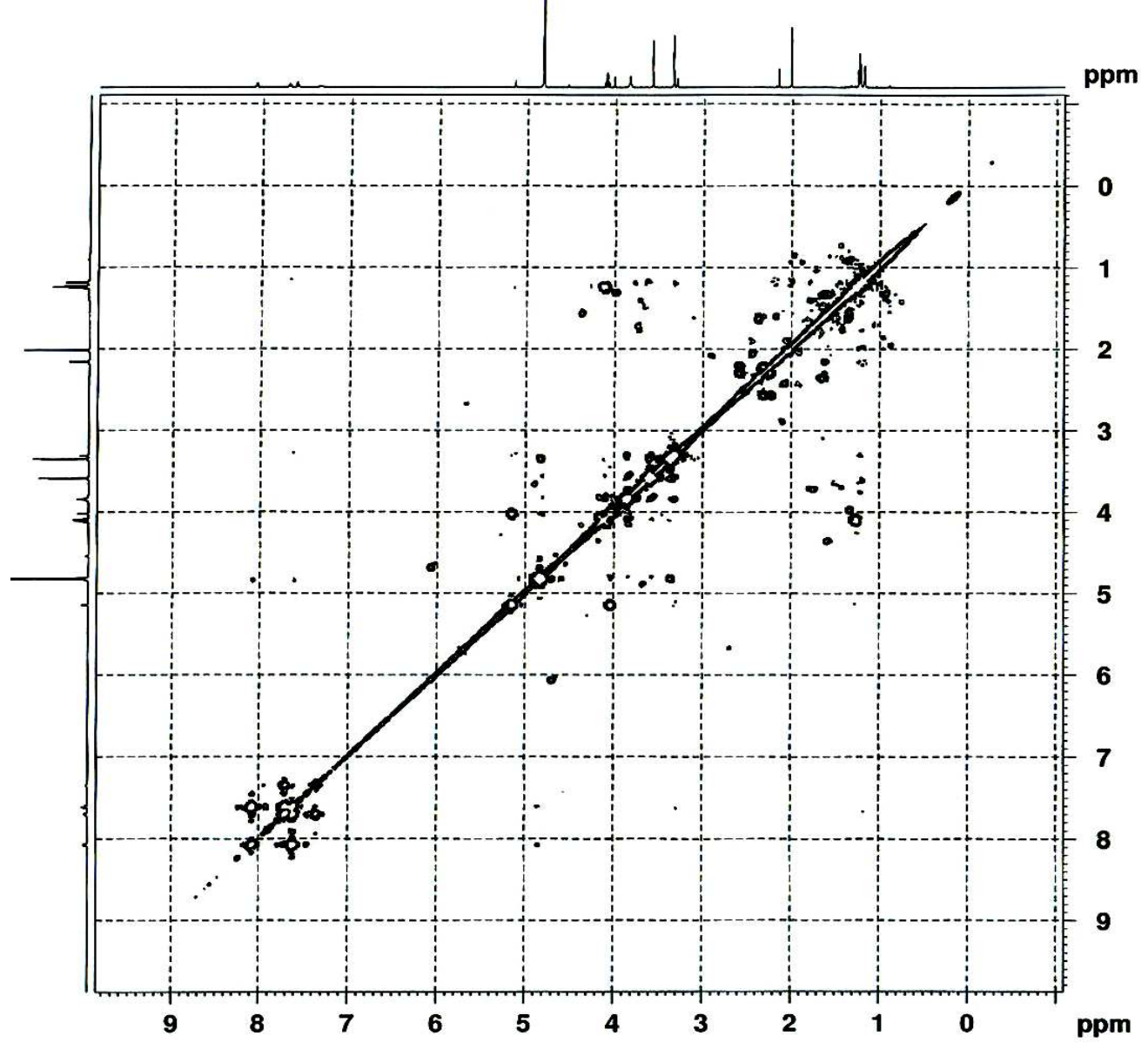

Fig. 13. COSY spectrum of 2

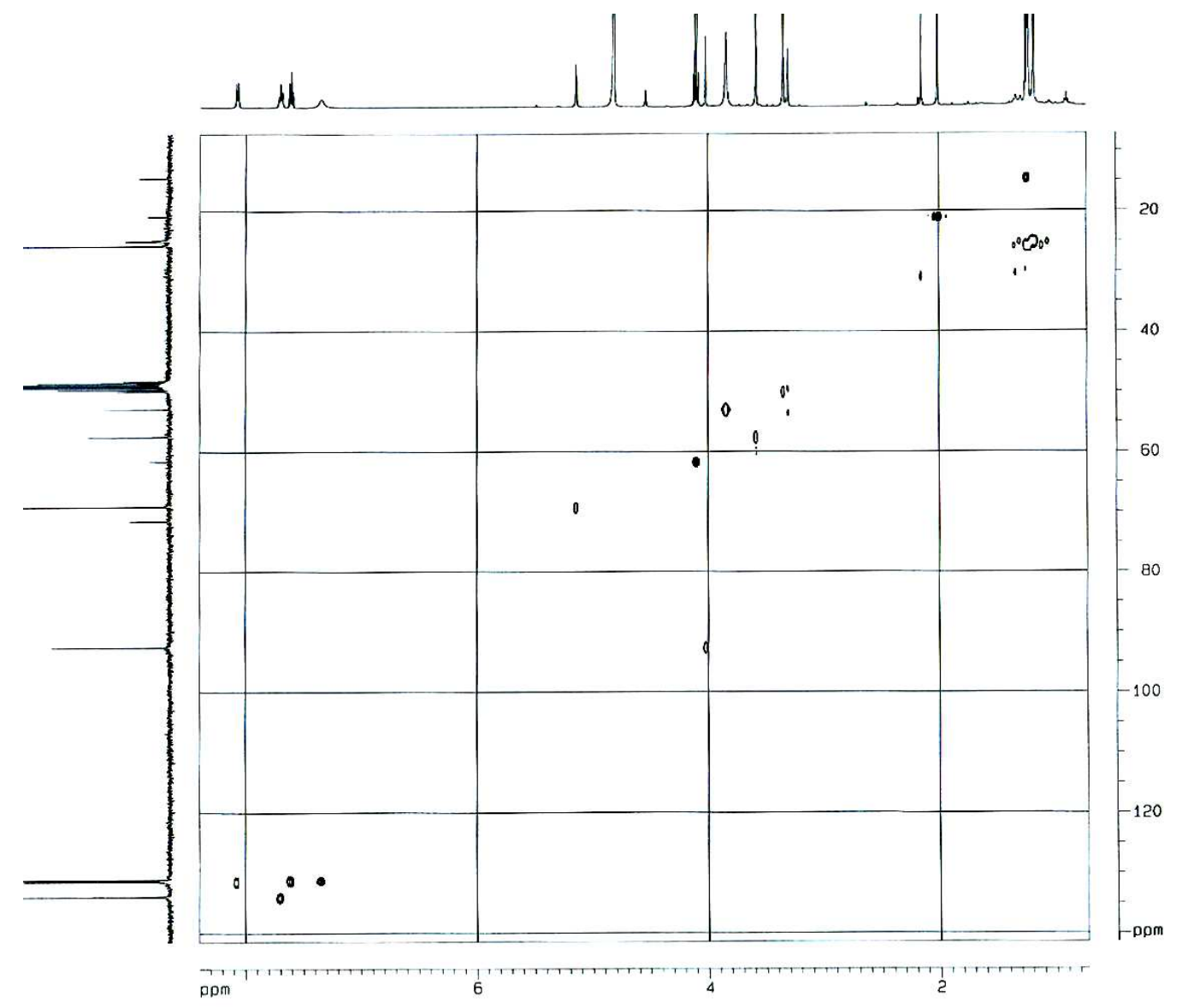

Fig. 14. HMQC spectrum of 2 


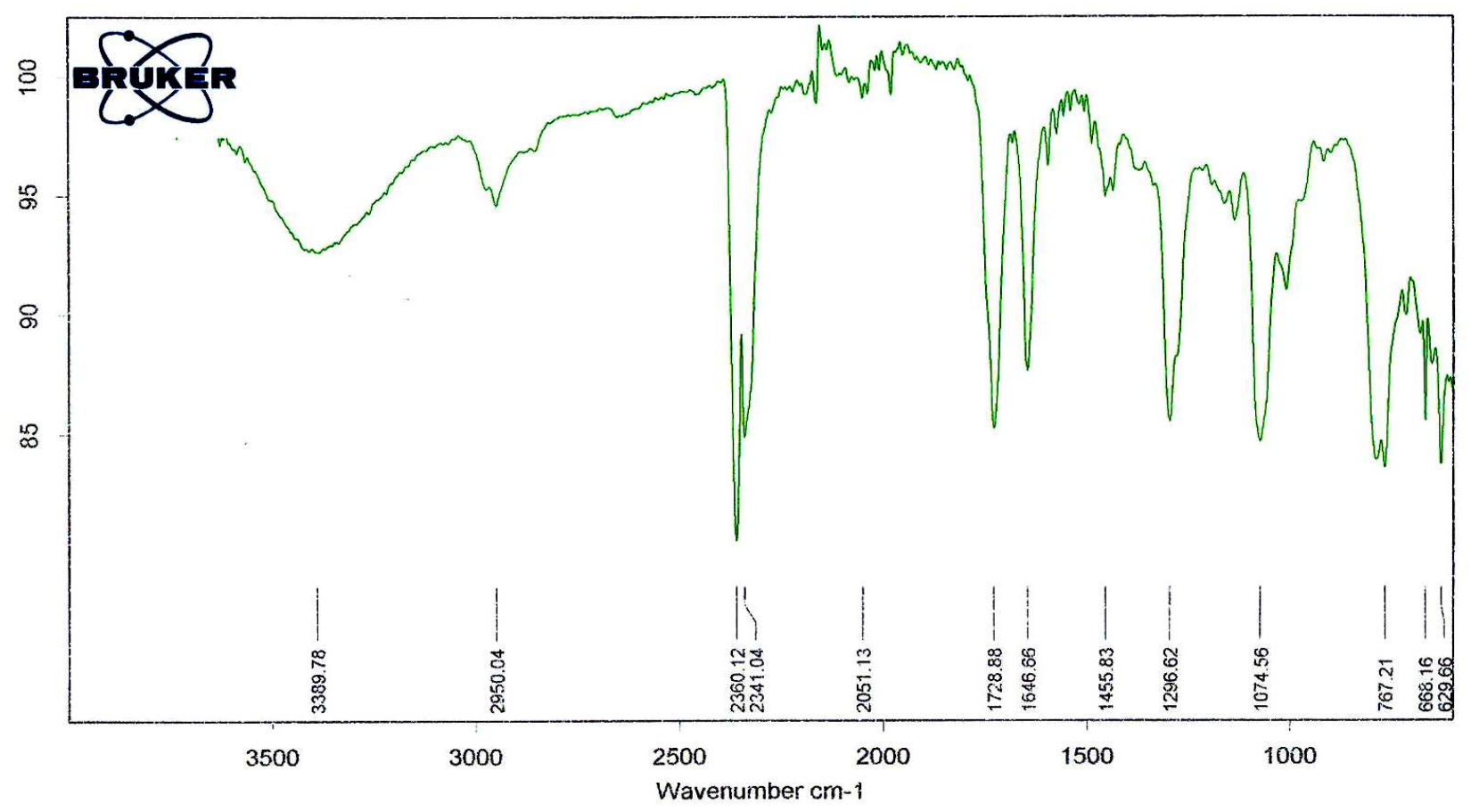

Fig. 17. IR spectrum of 2

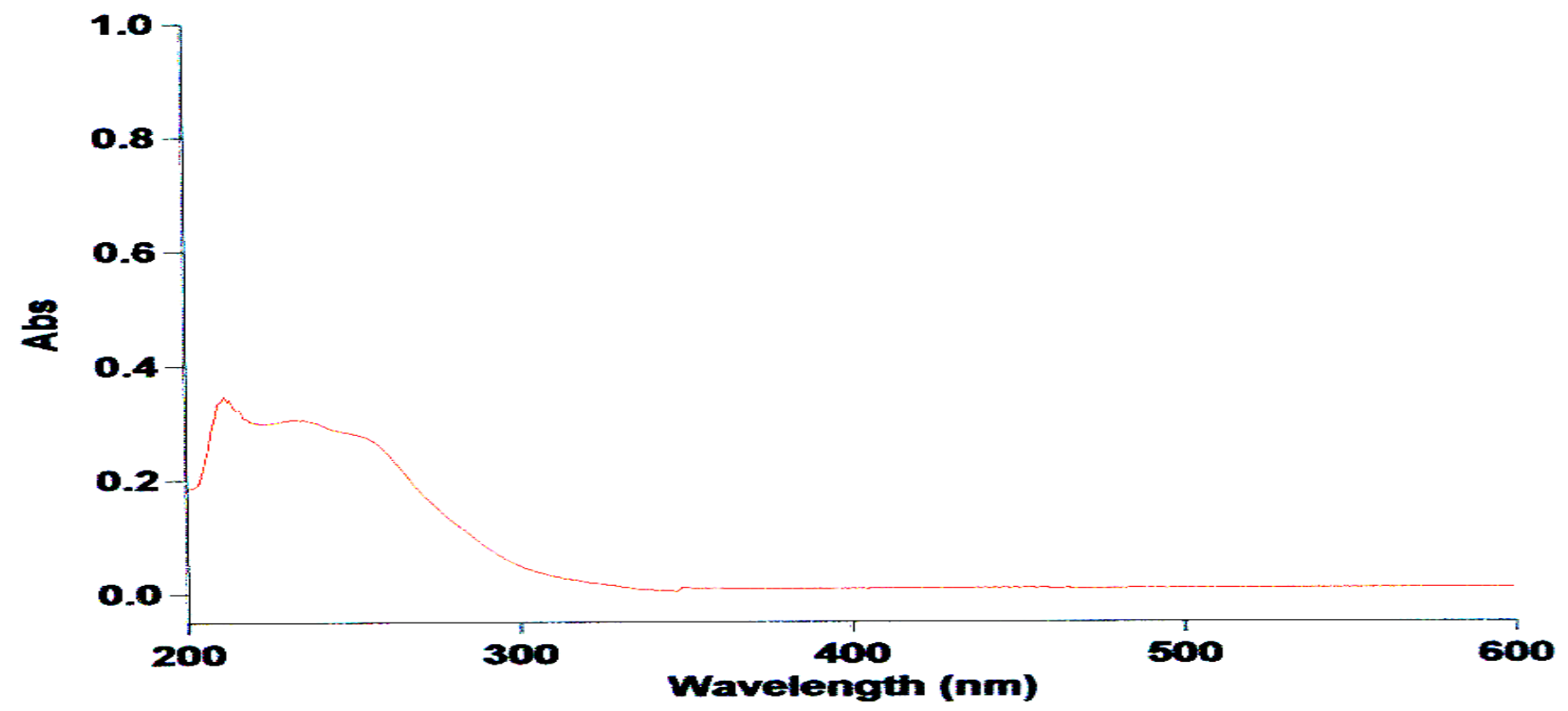

Fig. 18. UV $\left(\mathrm{CH}_{3} \mathrm{OH}\right)$ spectrum of 2 
07012908Heinecke \#1-19 RT: 0.02-0.37 AV: 19 NL: $2.04 E 7$

$\mathrm{T}:$ + c Q3MS [ 100.00-800.00]

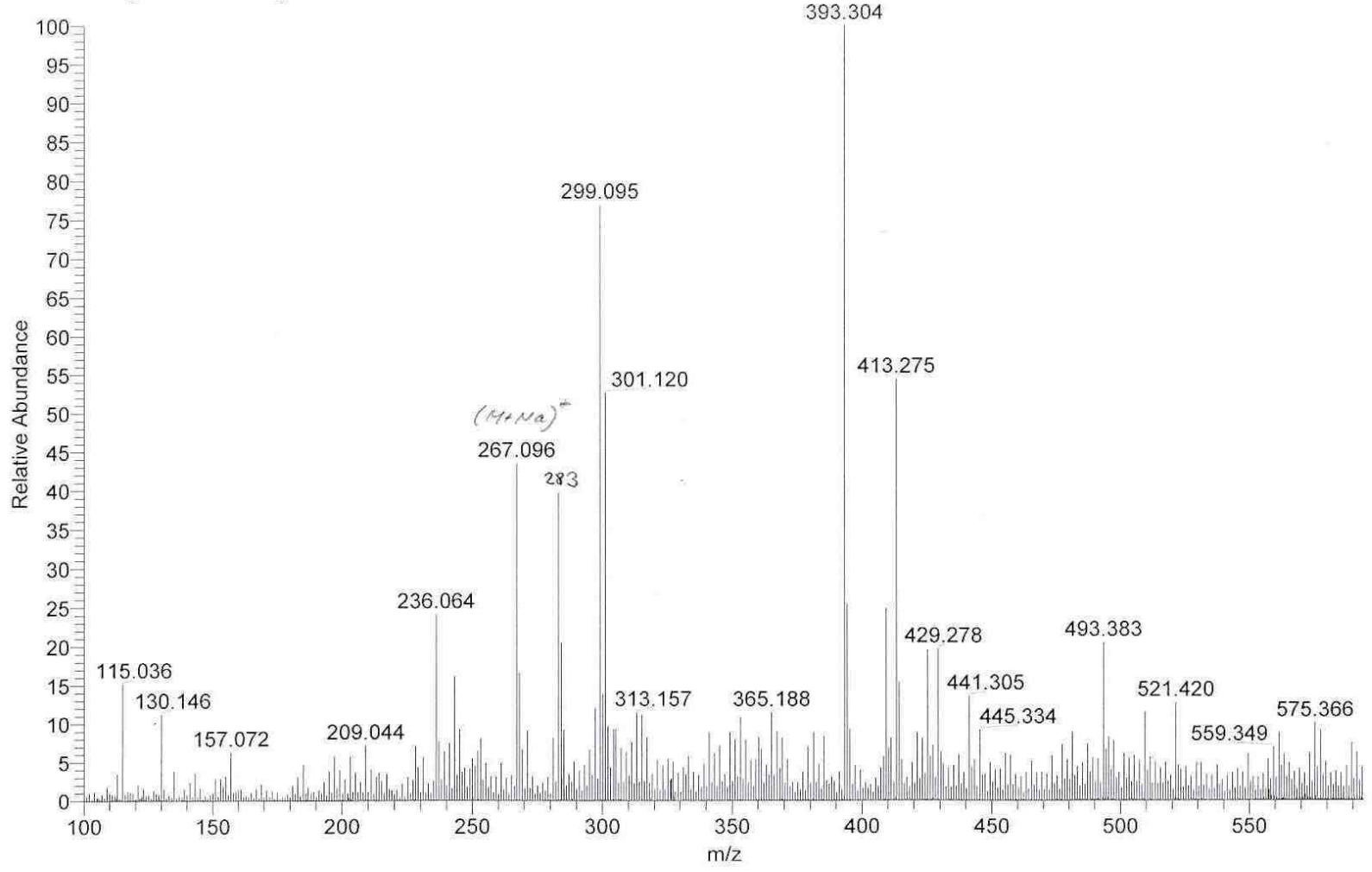

Fig. 19. ESI-MS spectrum of $\mathbf{3}$

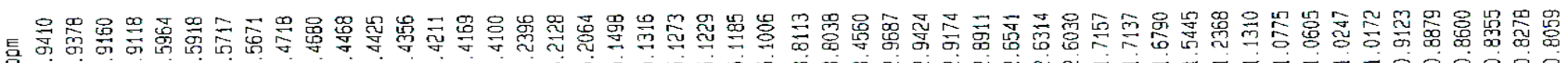
ríli $\Rightarrow$
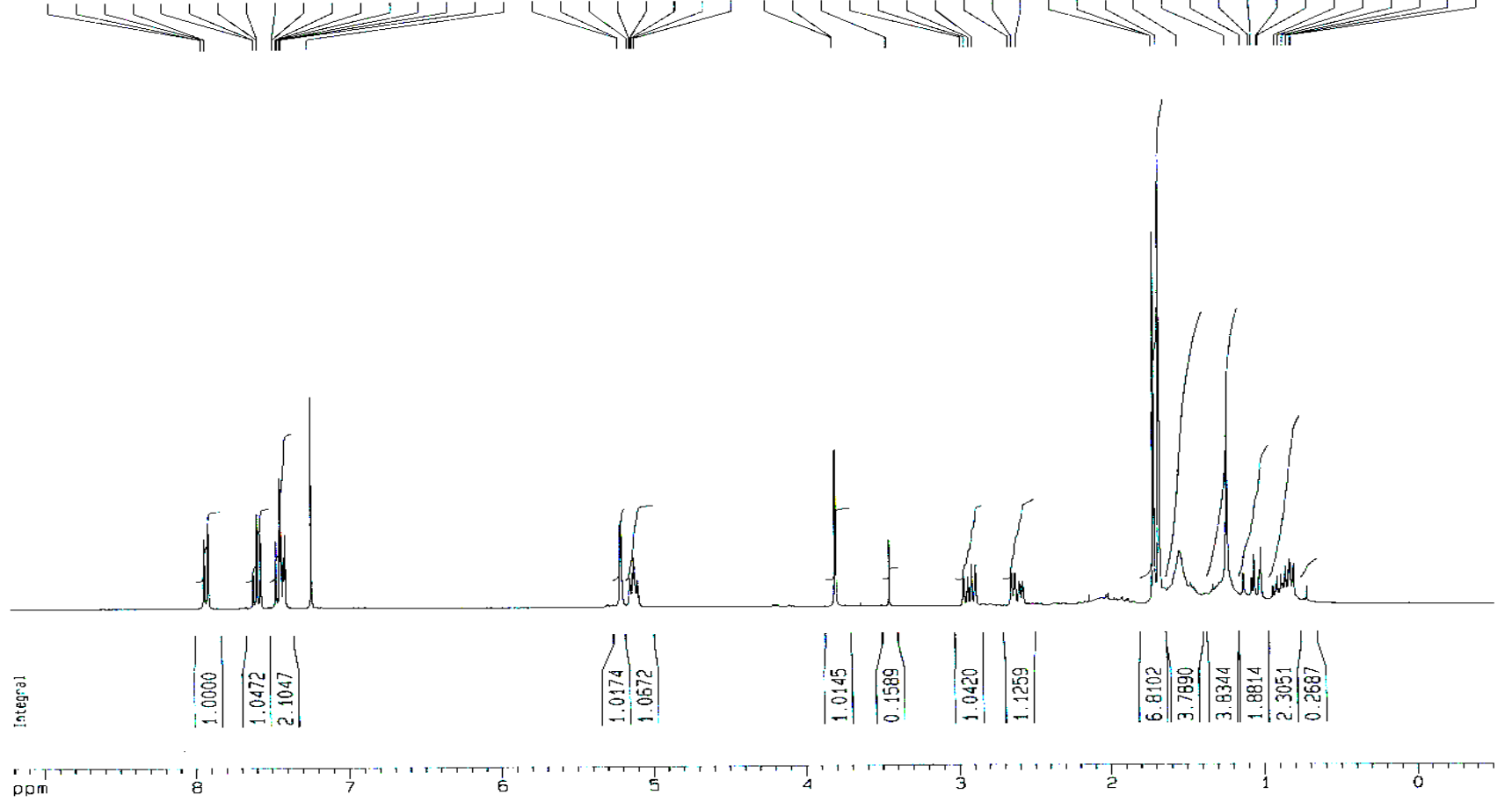

Fig. 20. ${ }^{1} \mathrm{H}-\mathrm{NMR}$ spectrum of $\mathbf{3}$ 


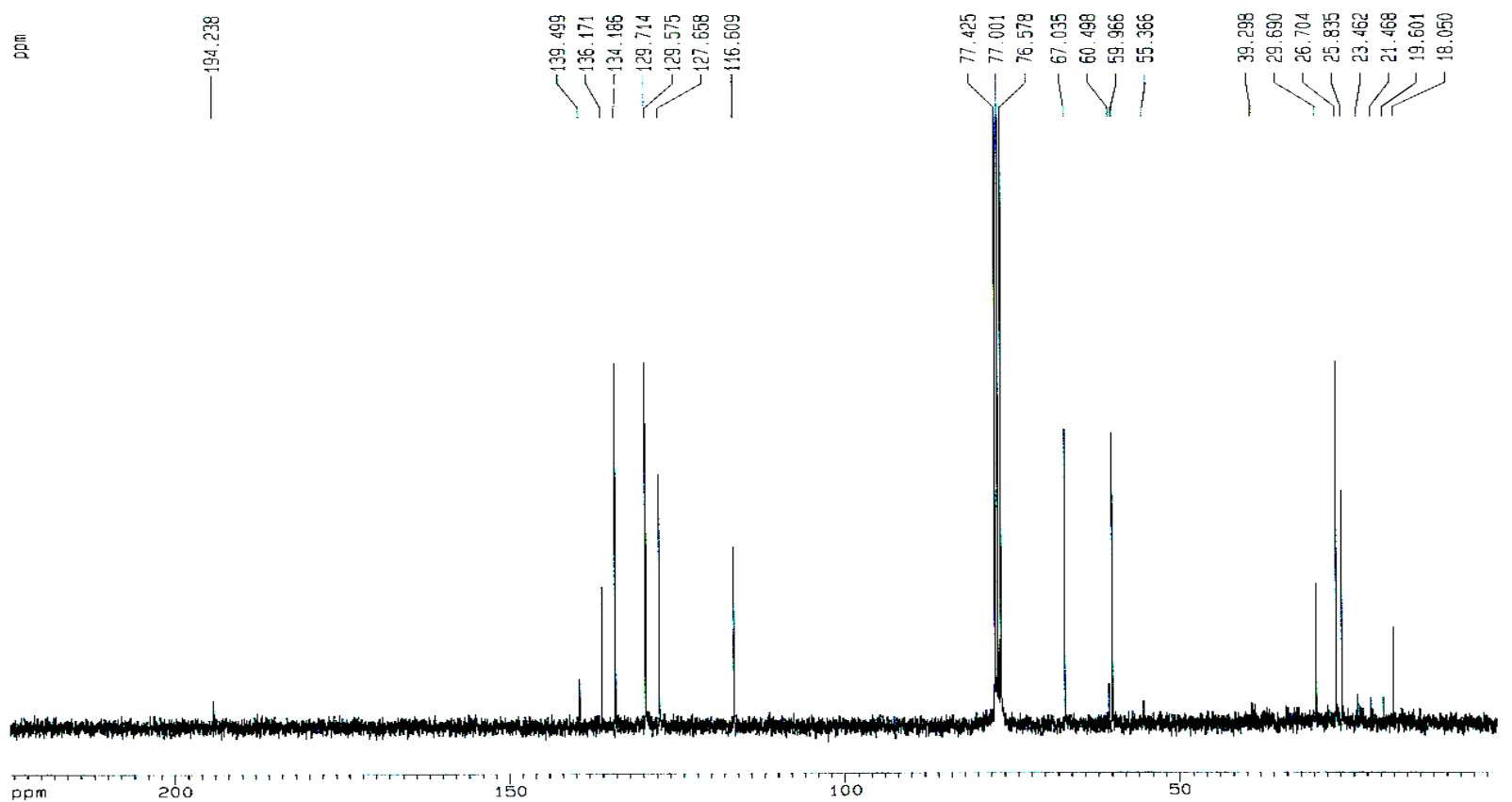

Fig. $21 .{ }^{13} \mathrm{C}-\mathrm{NMR}$ spectrum of $\mathbf{3}$

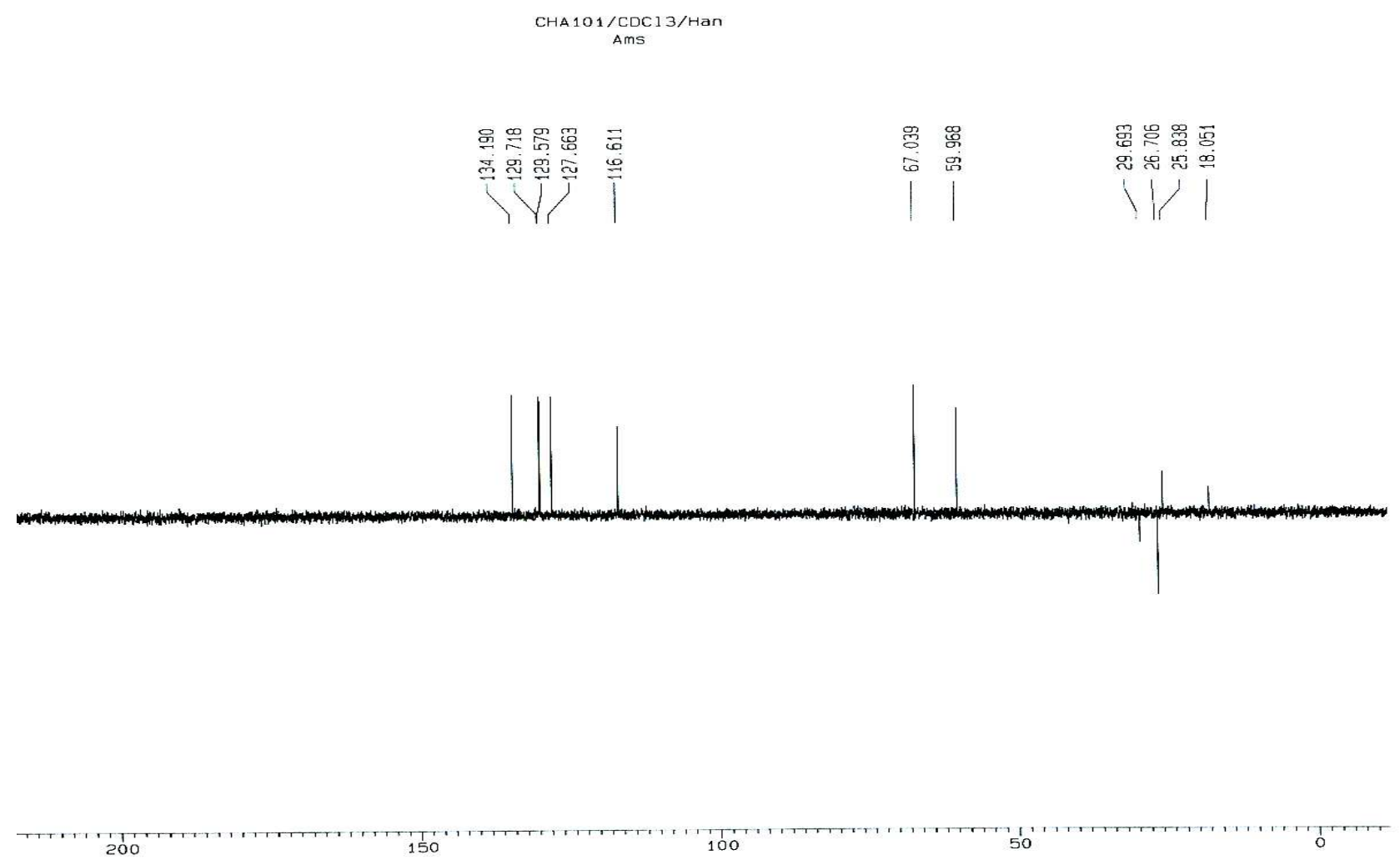

Fig. 22. DEPT spectrum of $\mathbf{3}$ 


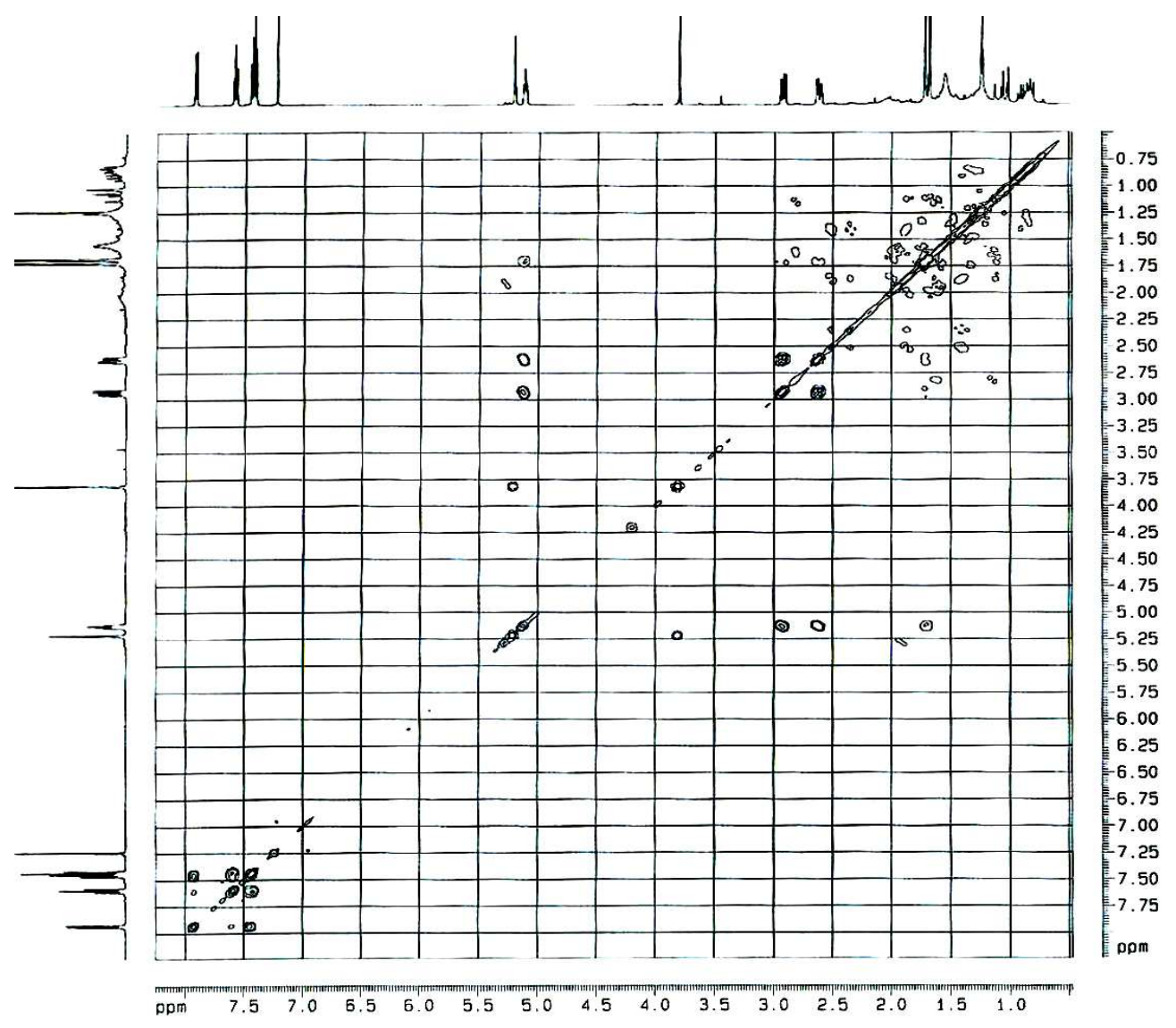

Fig. 23. COSY spectrum of 3

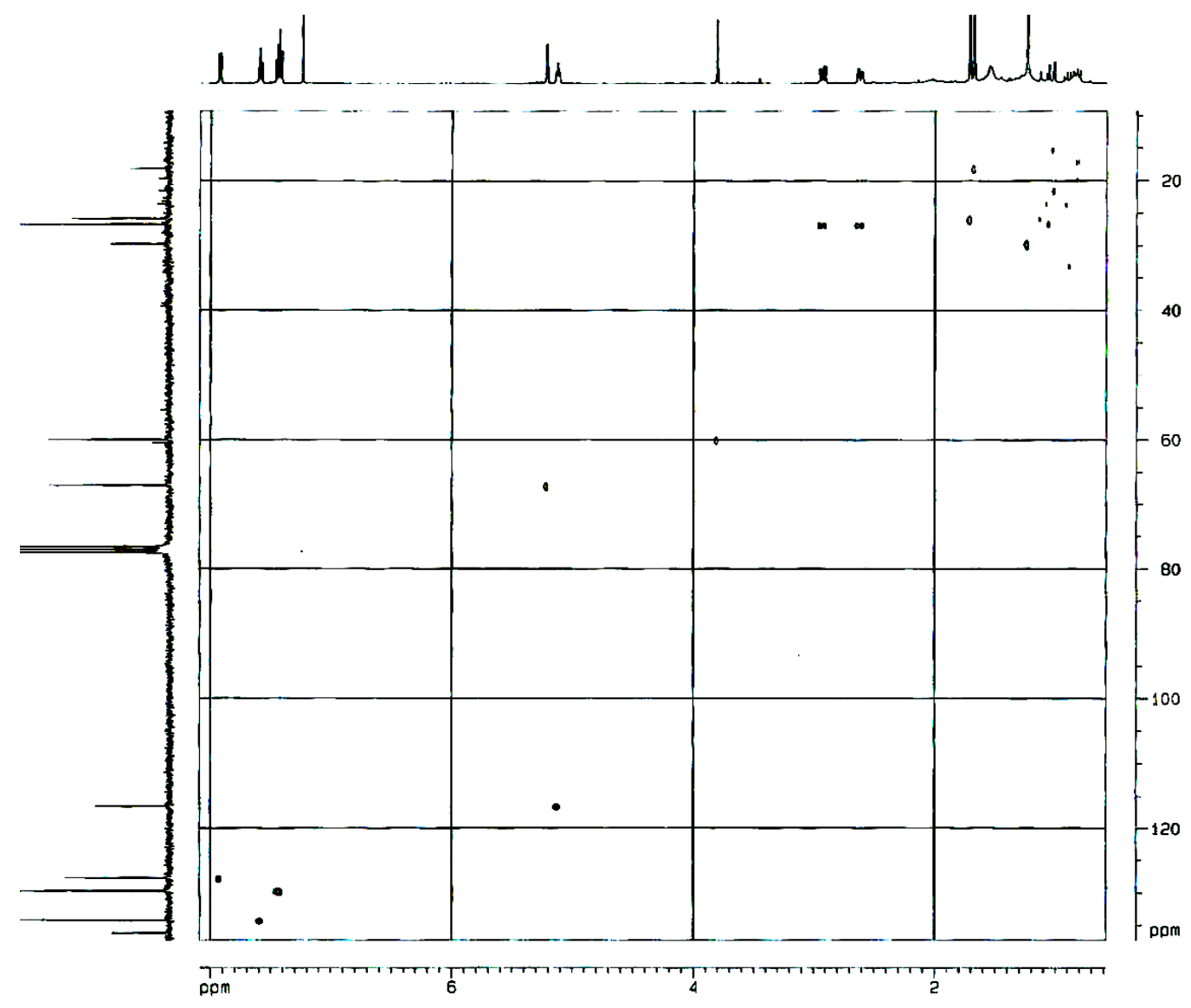

Fig. 24. HMQC spectrum of $\mathbf{3}$ 


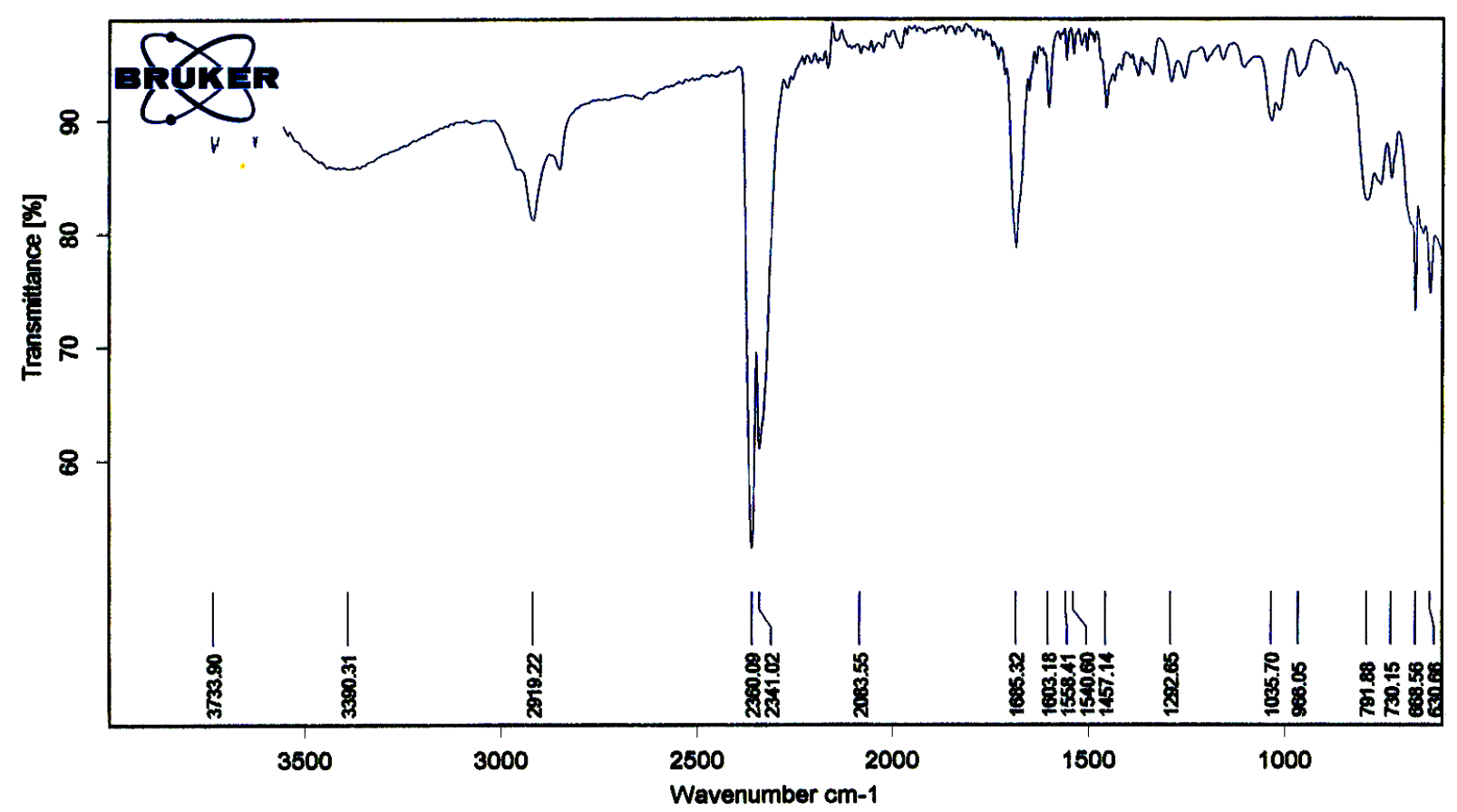

Fig. 27. IR spectrum of $\mathbf{3}$

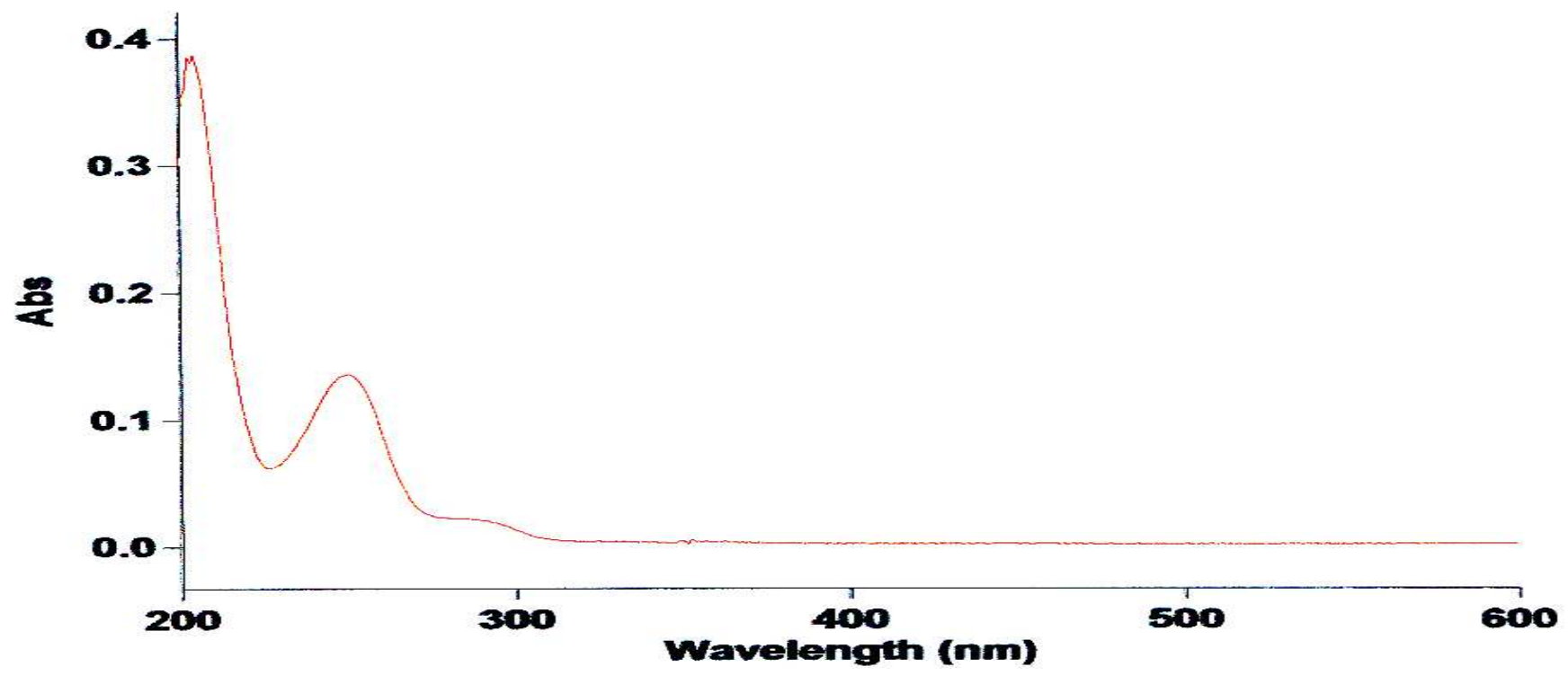

Fig. 28. UV $\left(\mathrm{CH}_{3} \mathrm{OH}\right)$ spectrum of $\mathbf{3}$ 


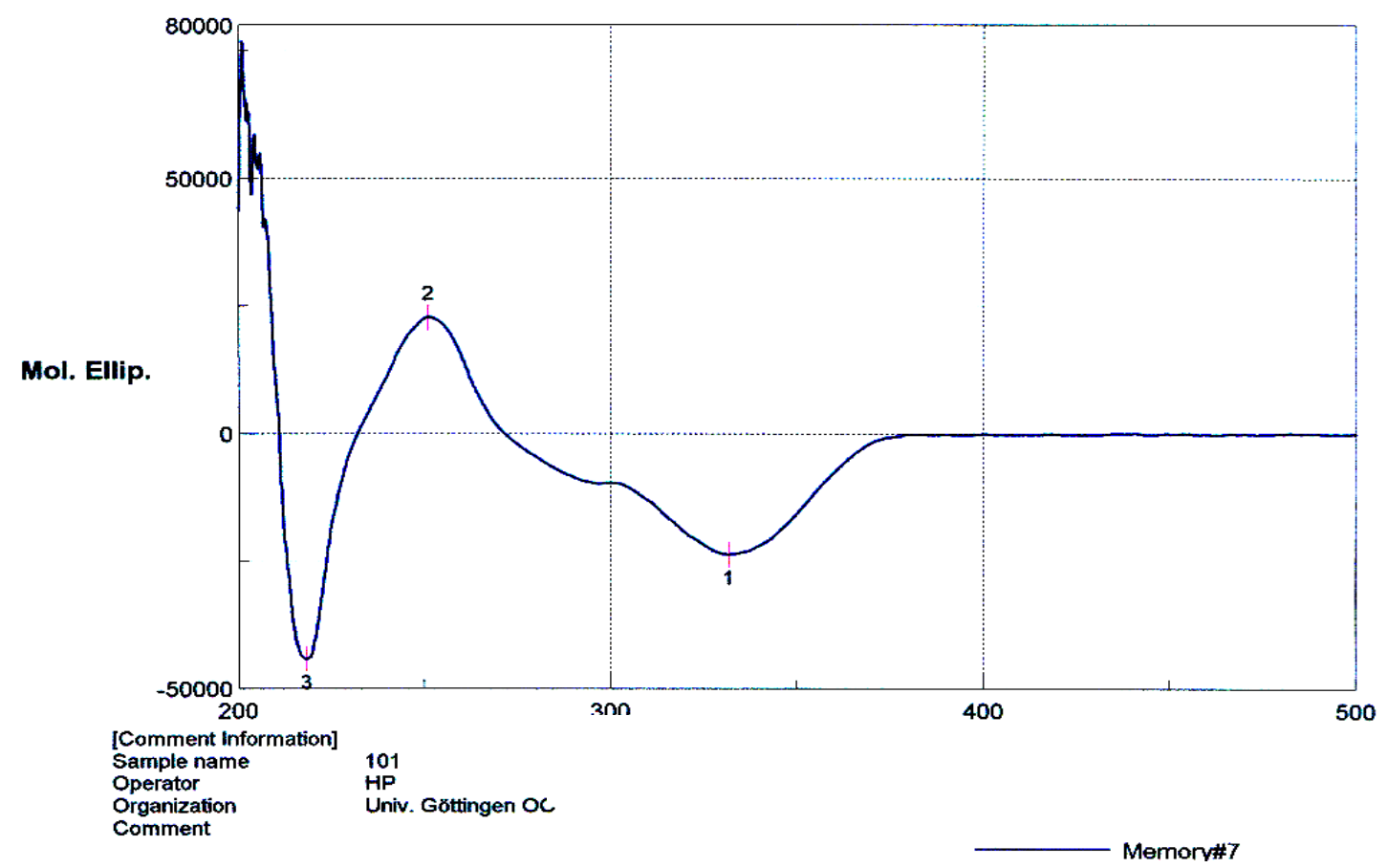

Fig. 20. CD spectrum of $\mathbf{3}$

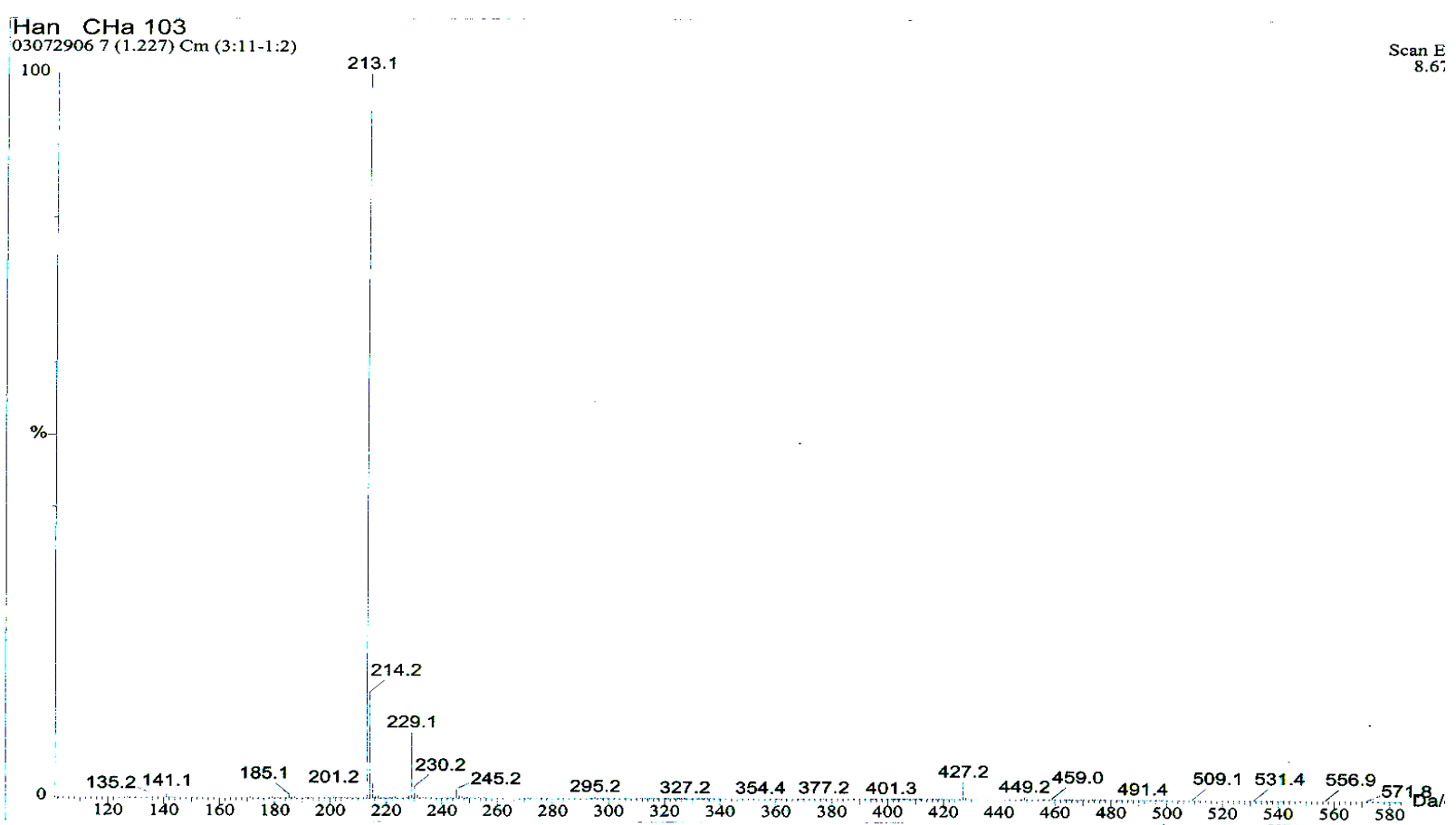

Fig. 30. ESI-MS spectrum of 4-5 


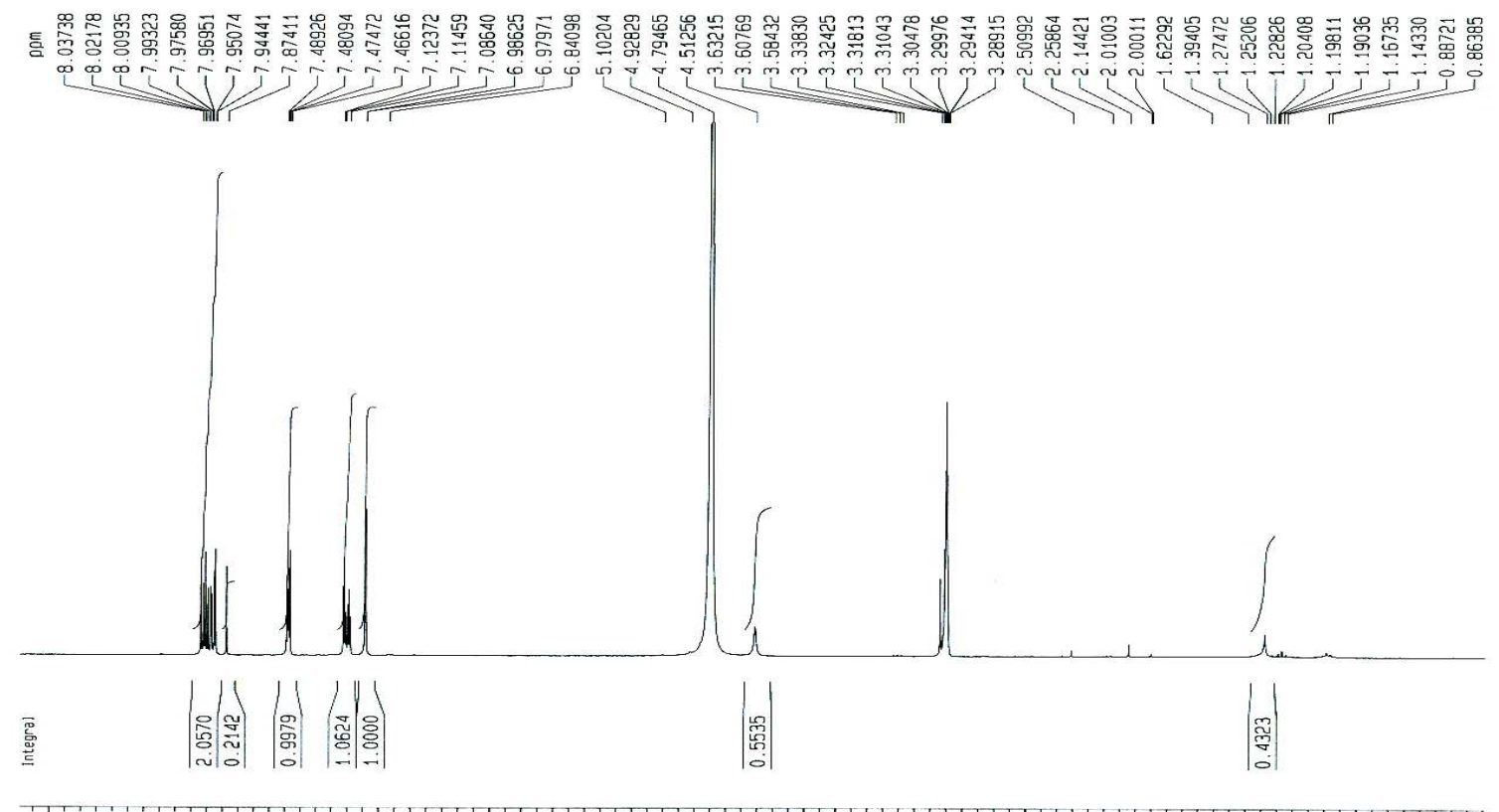

Fig. 31. ${ }^{1}$ H-NMR spectrum of $\mathbf{4 - 5}$

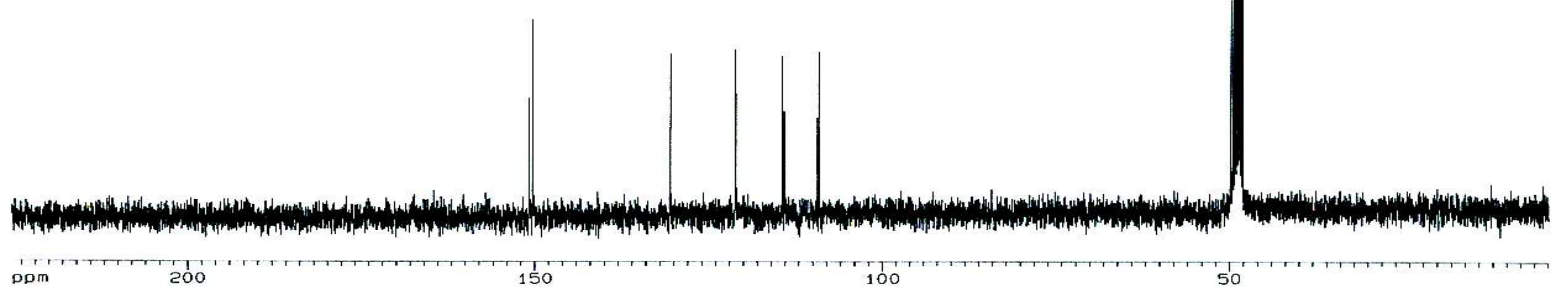

Fig. $32 .{ }^{13} \mathrm{C}-\mathrm{NMR}$ spectrum of $\mathbf{4 - 5}$ 


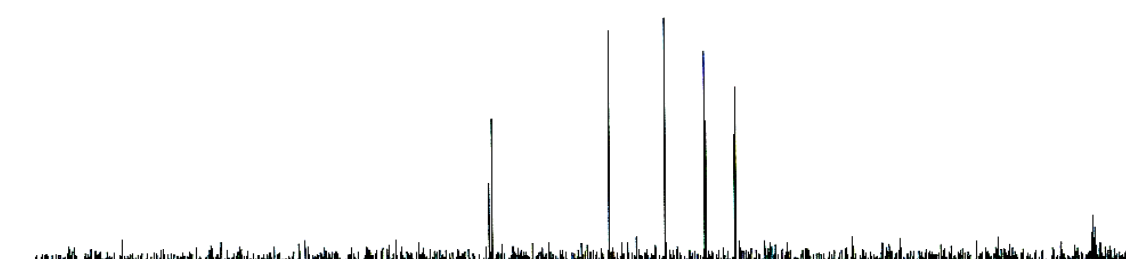

(n)

Fig. 33. DEPT spectrum of $\mathbf{4 - 5}$

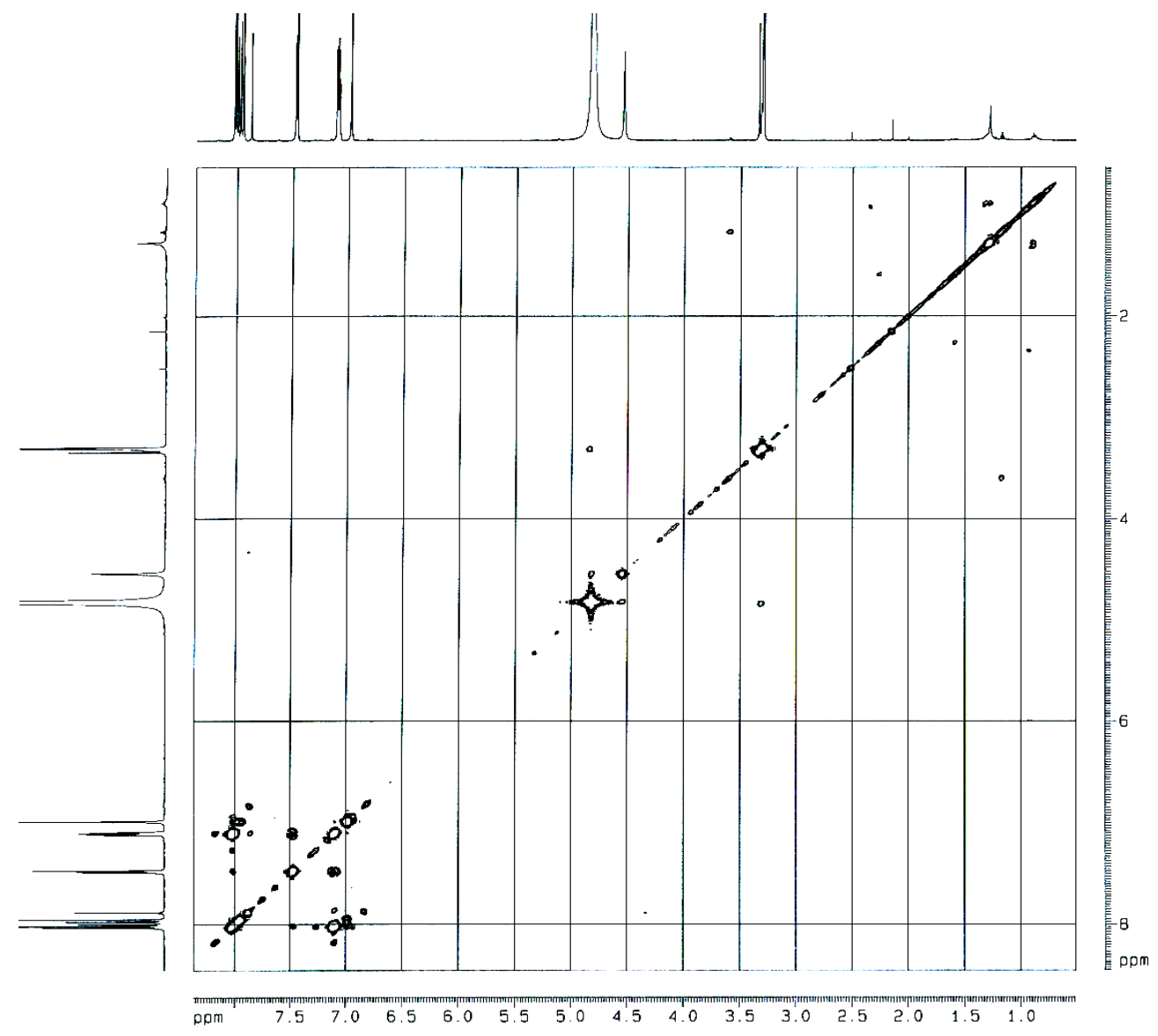

Fig. 34. COSY spectrum of 4-5 


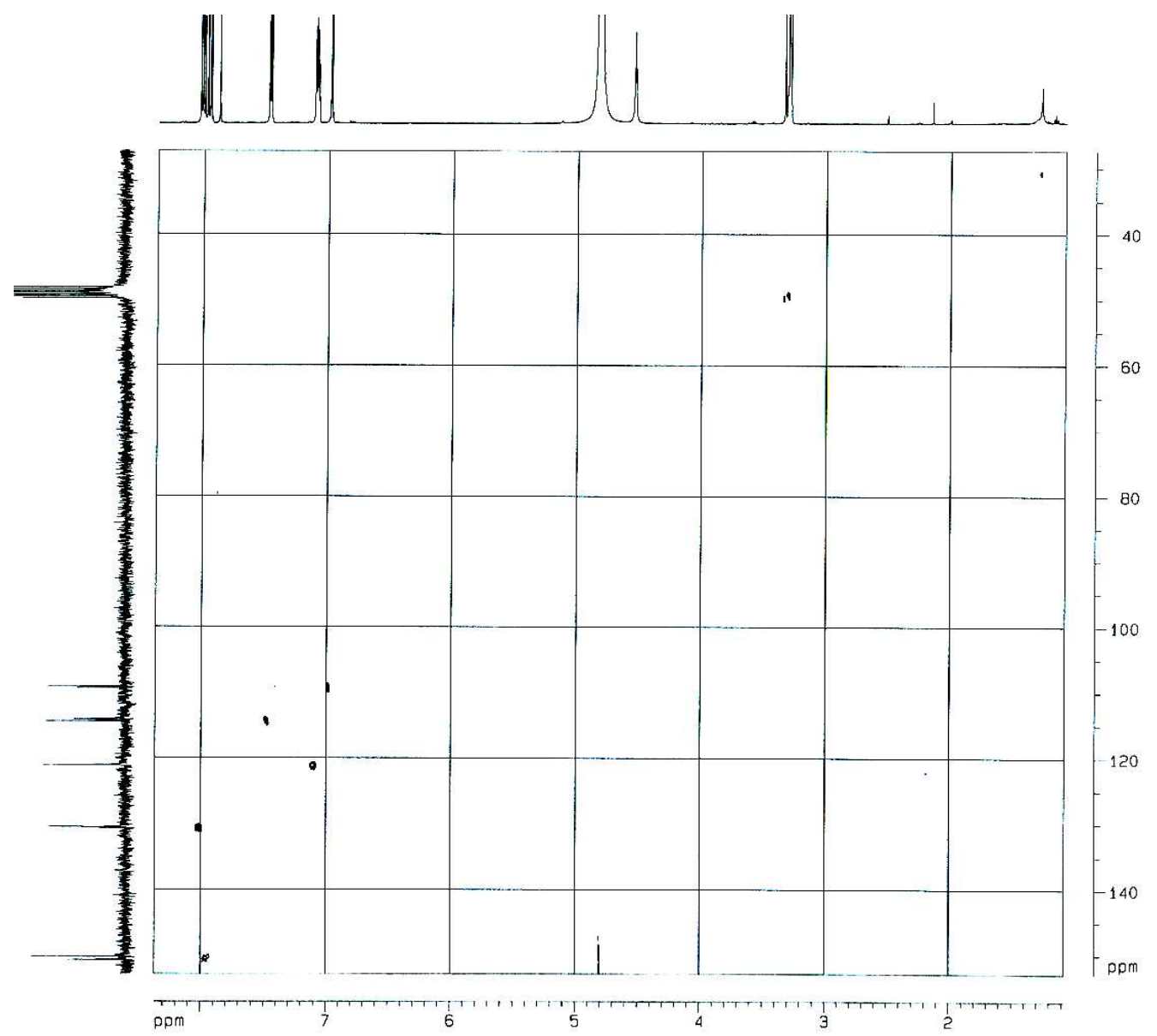

Fig. 35. HMQC spectrum of 4-5

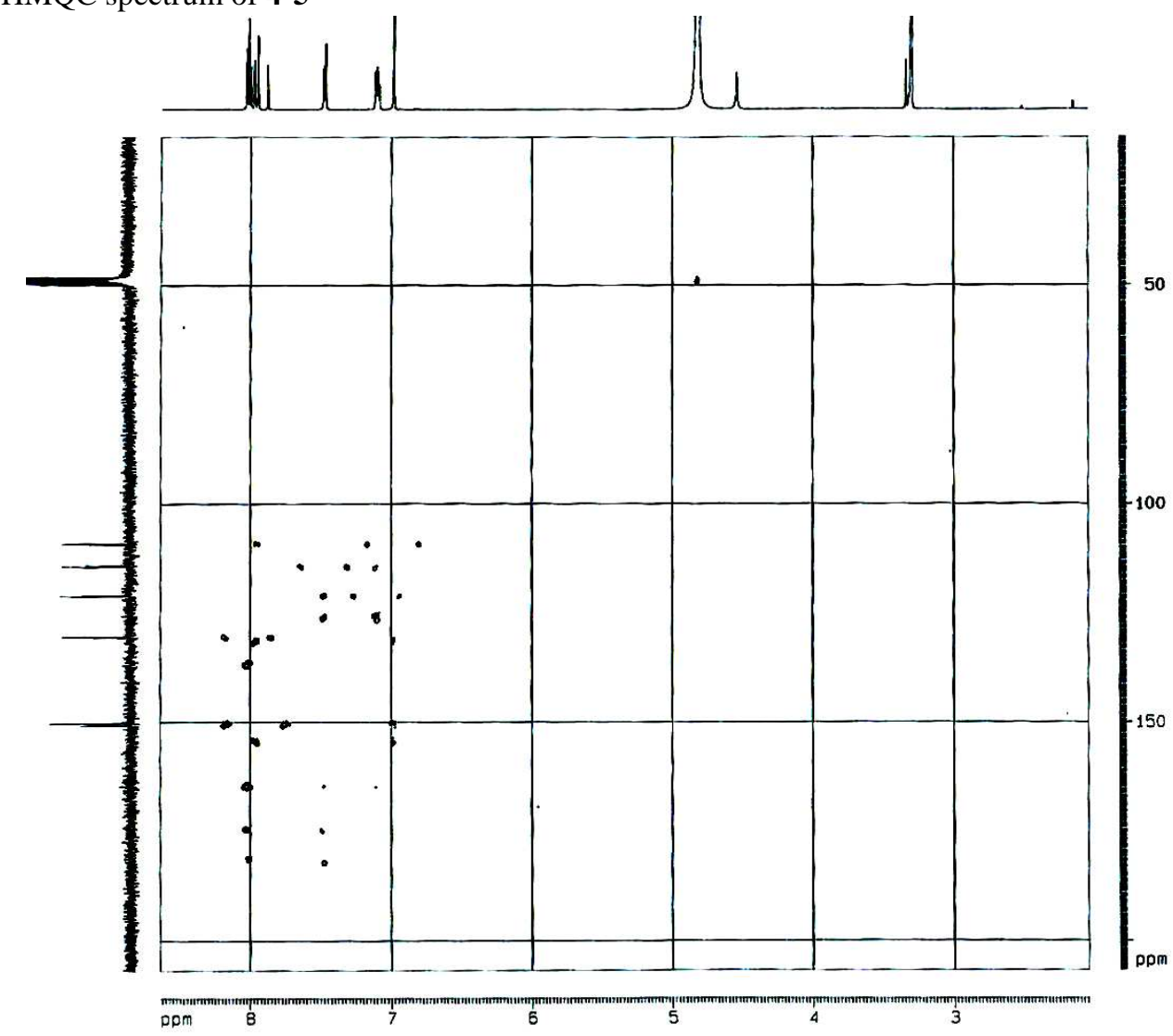

Fig. 36. HMBC spectrum of $\mathbf{4 - 5}$ 


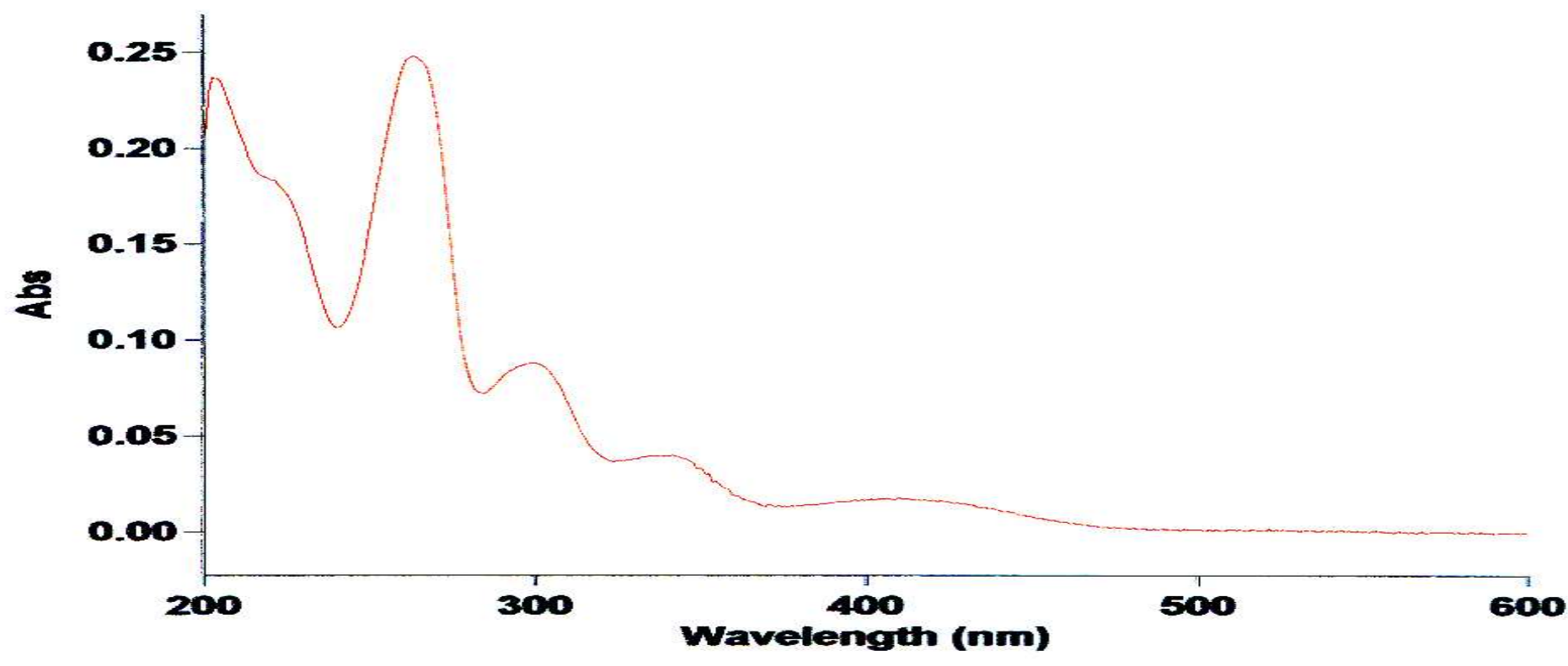

Fig. 39. UV $\left(\mathrm{CH}_{3} \mathrm{OH}\right)$ spectrum of $\mathbf{4 - 5}$

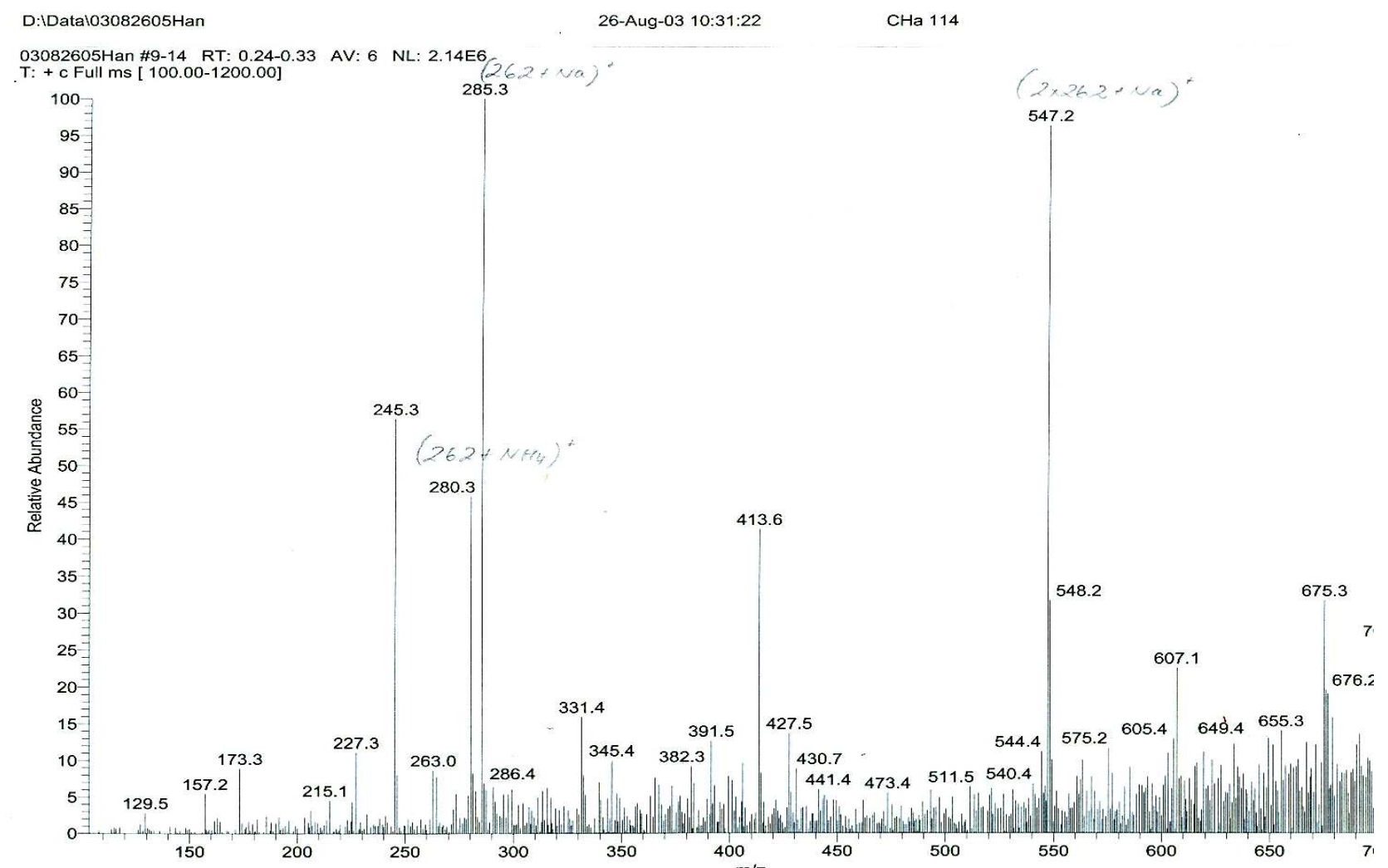

Fig. 40. ESI-MS spectrum of 6 


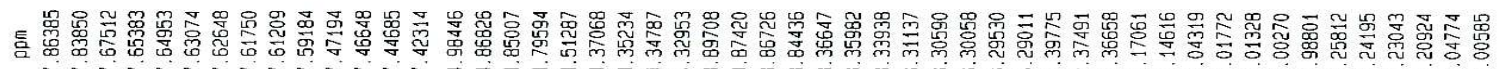

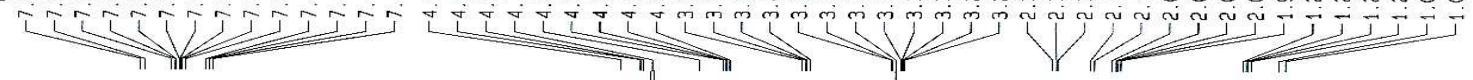

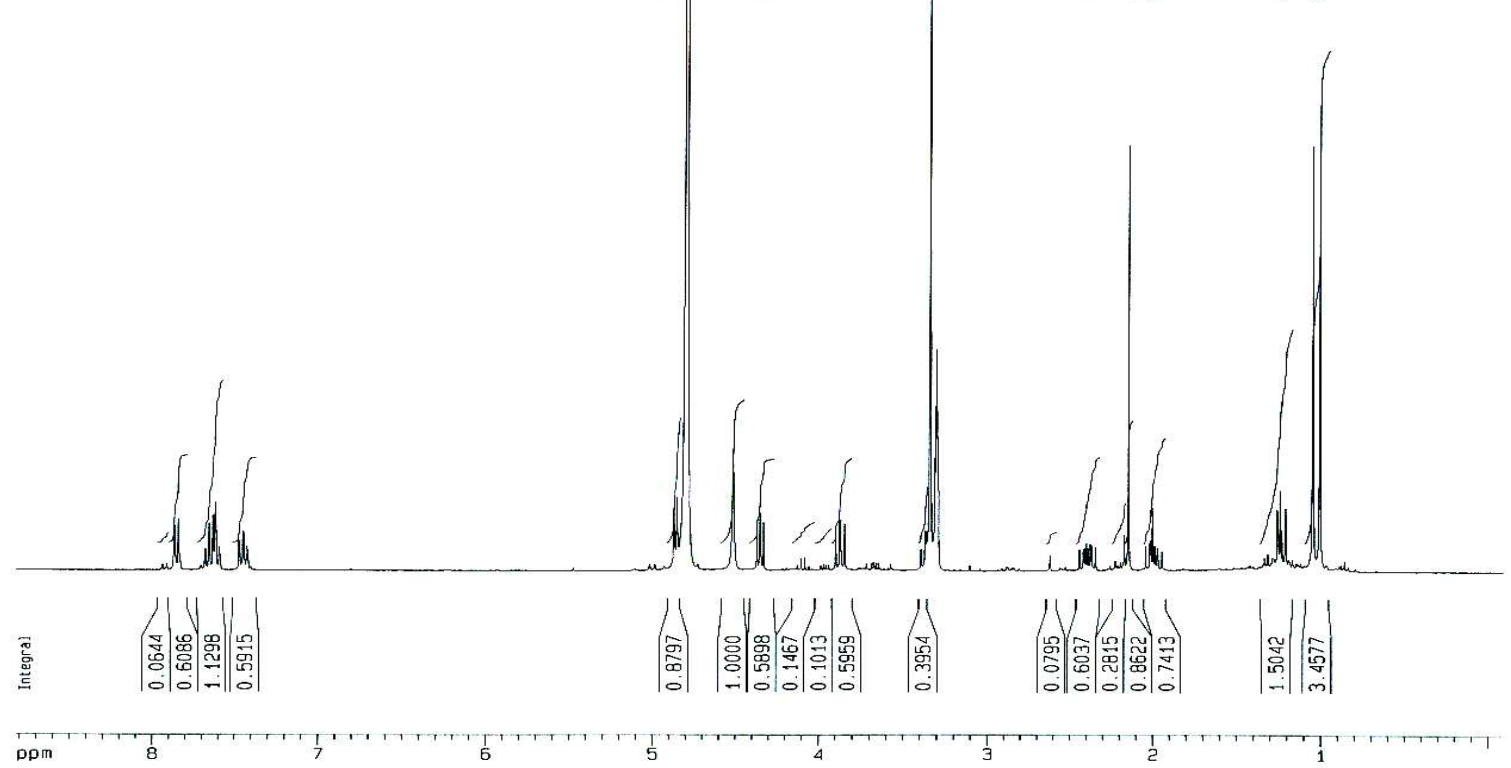

Fig. 41. ${ }^{1} \mathrm{H}-\mathrm{NMR}$ spectrum of $\mathbf{6}$

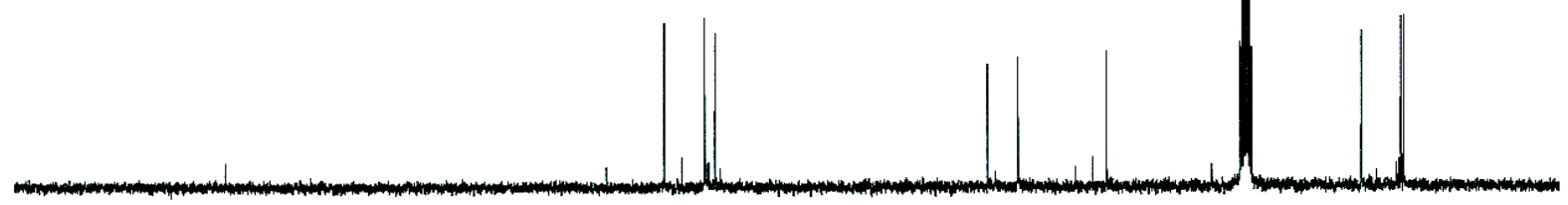

Fig. $42 .{ }^{13} \mathrm{C}$-NMR spectrum of 6 

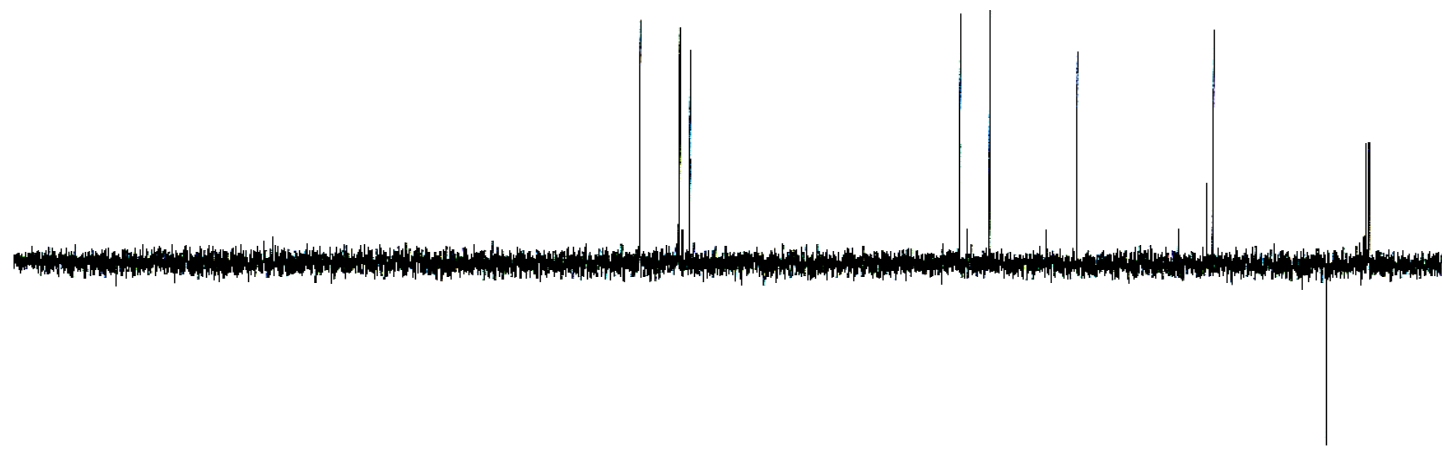

pom

200

$350^{12}$

Fig. 43. DEPT spectrum of 6

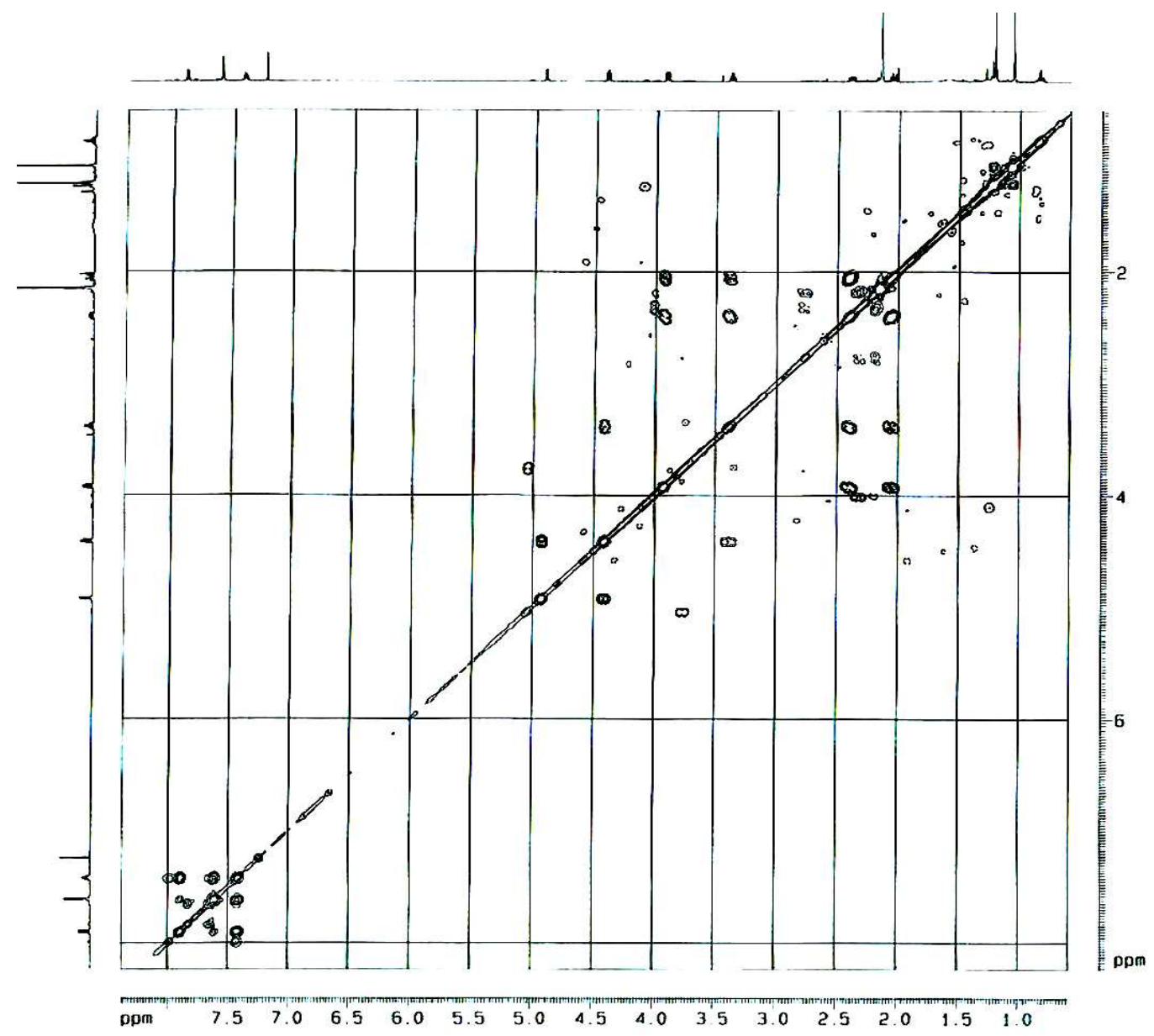

Fig. 44. COSY spectrum of 6 


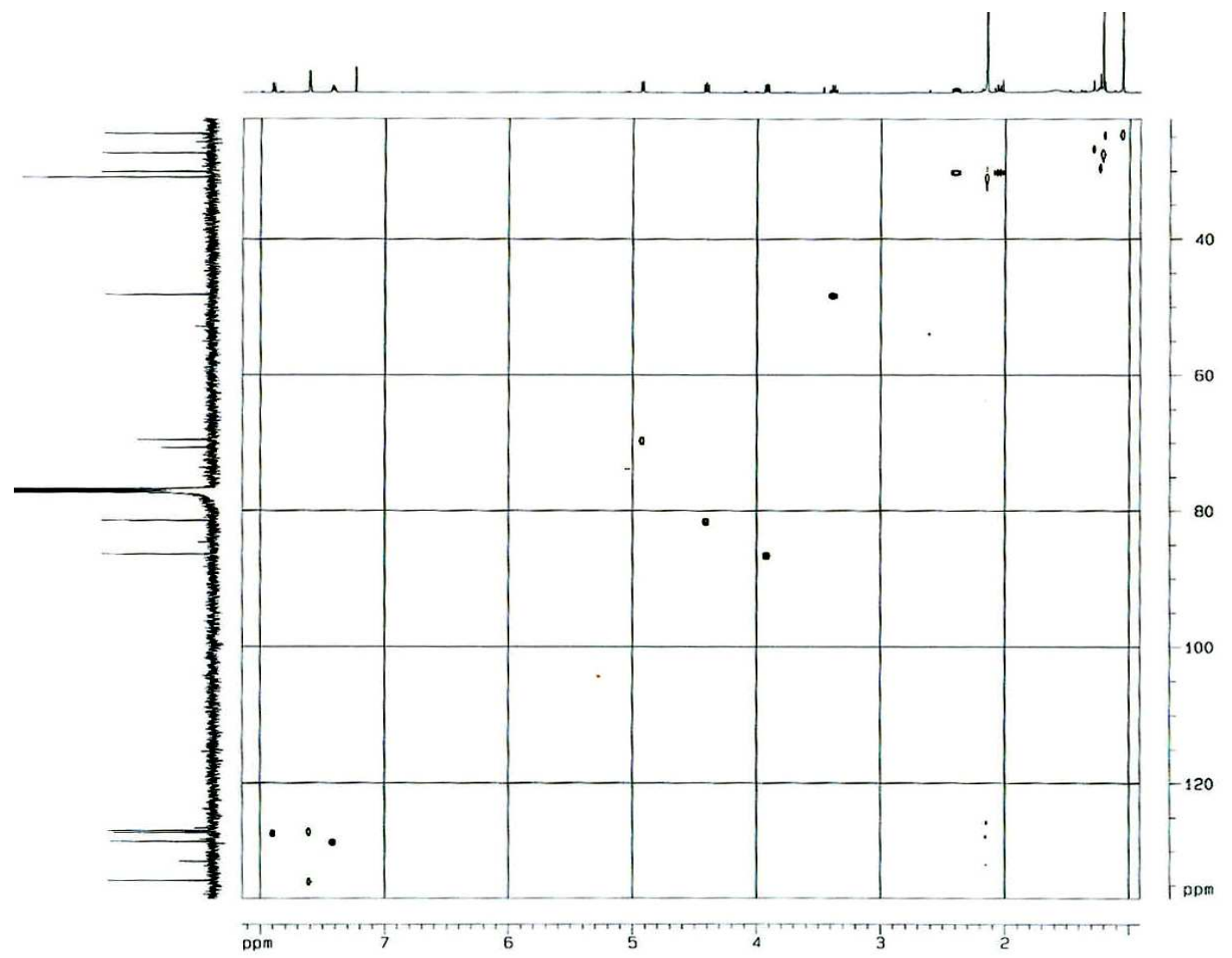

Fig. 45. HMQC spectrum of 6

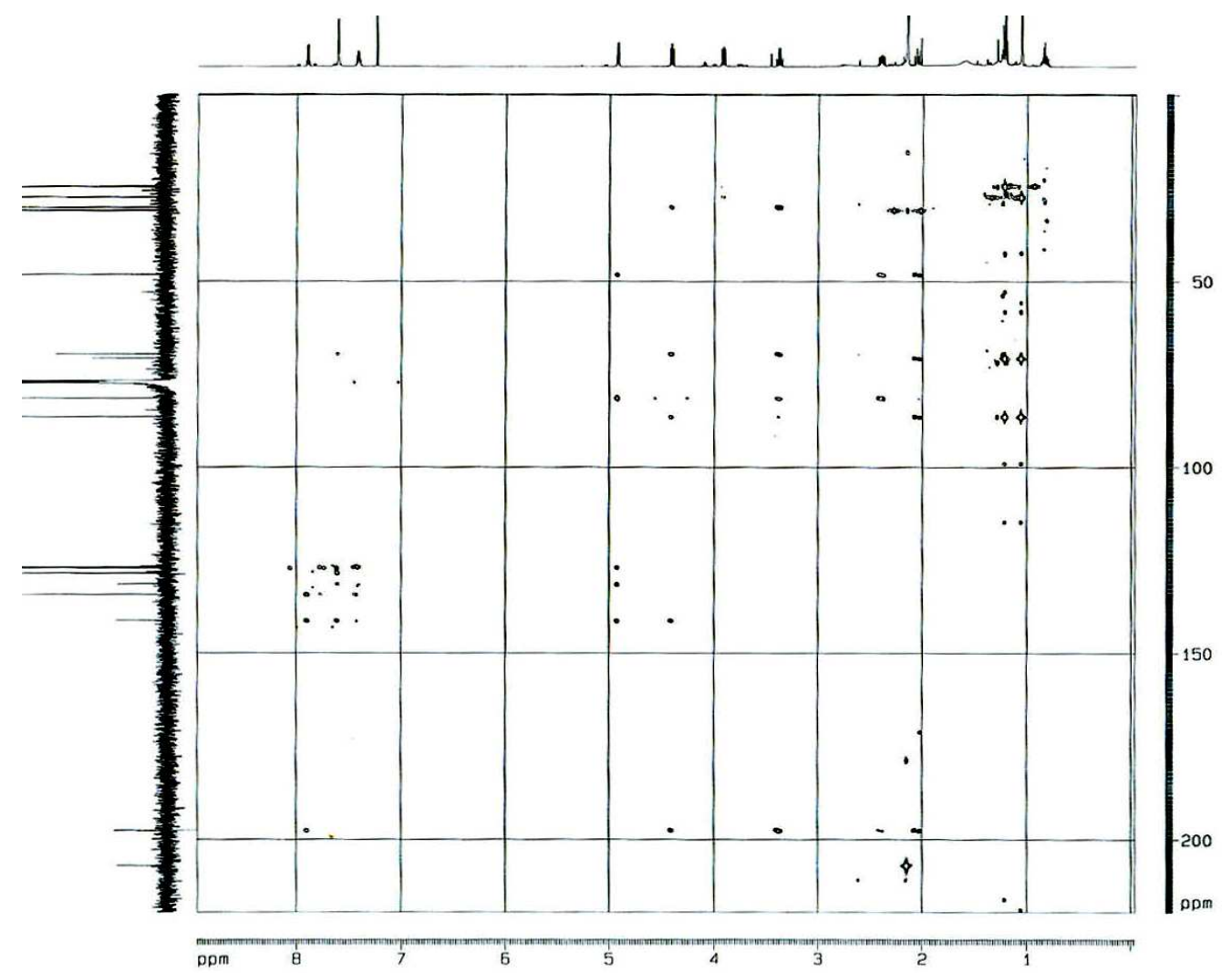

Fig. 46. HMBC spectrum of 6 


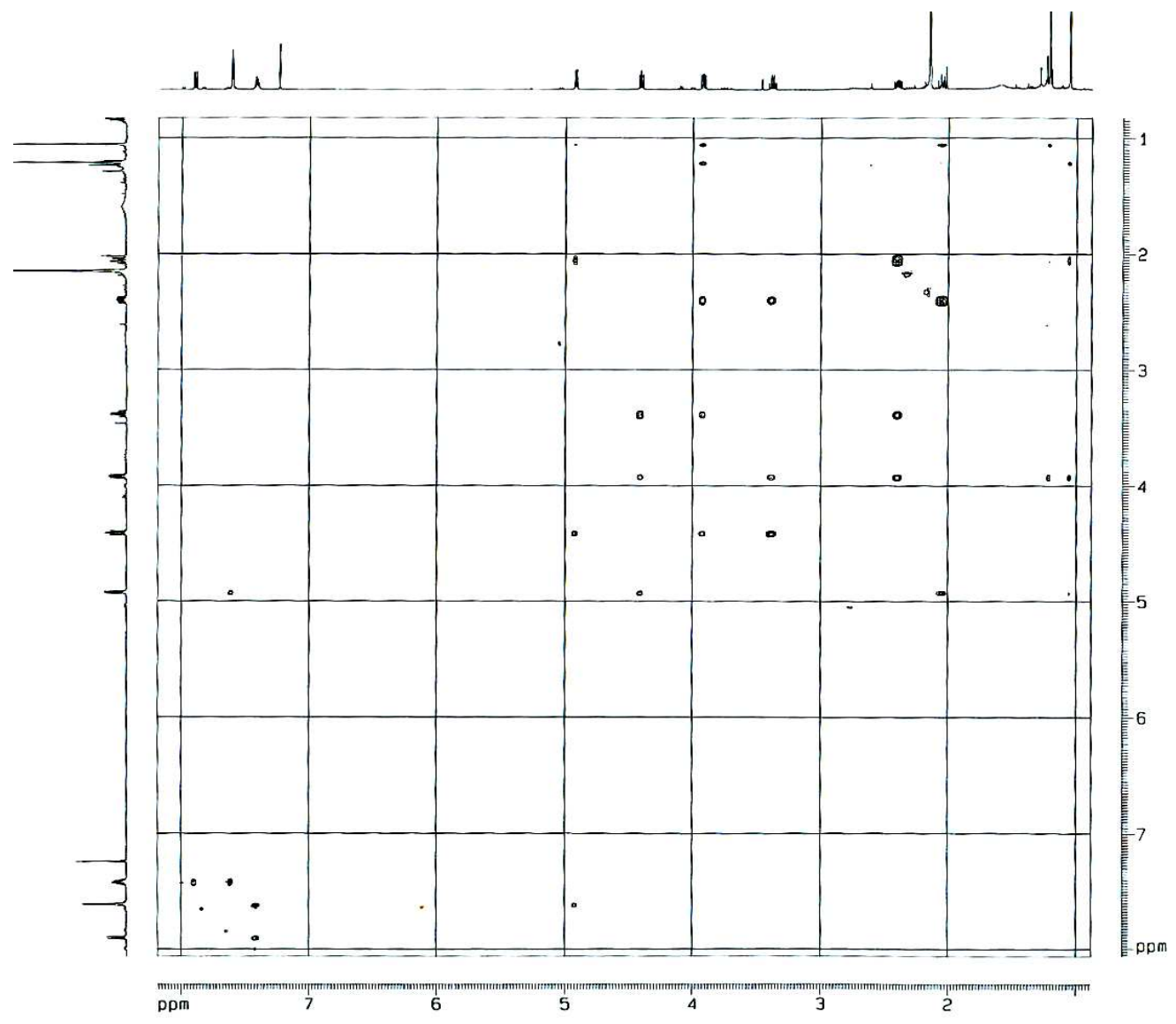

Fig. 47. NOESY spectrum of 6

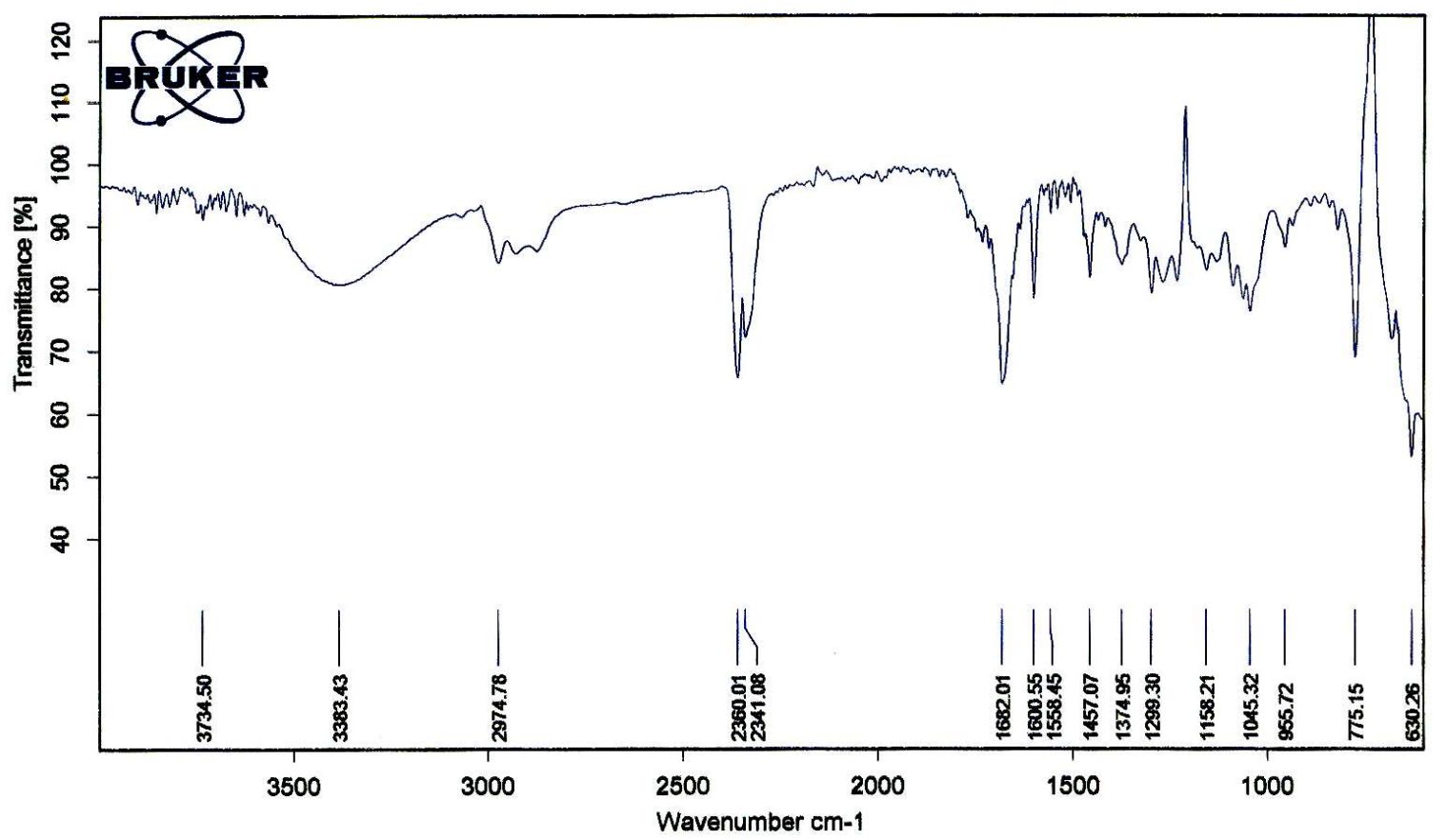

Fig. 48. IR spectrum of 6 


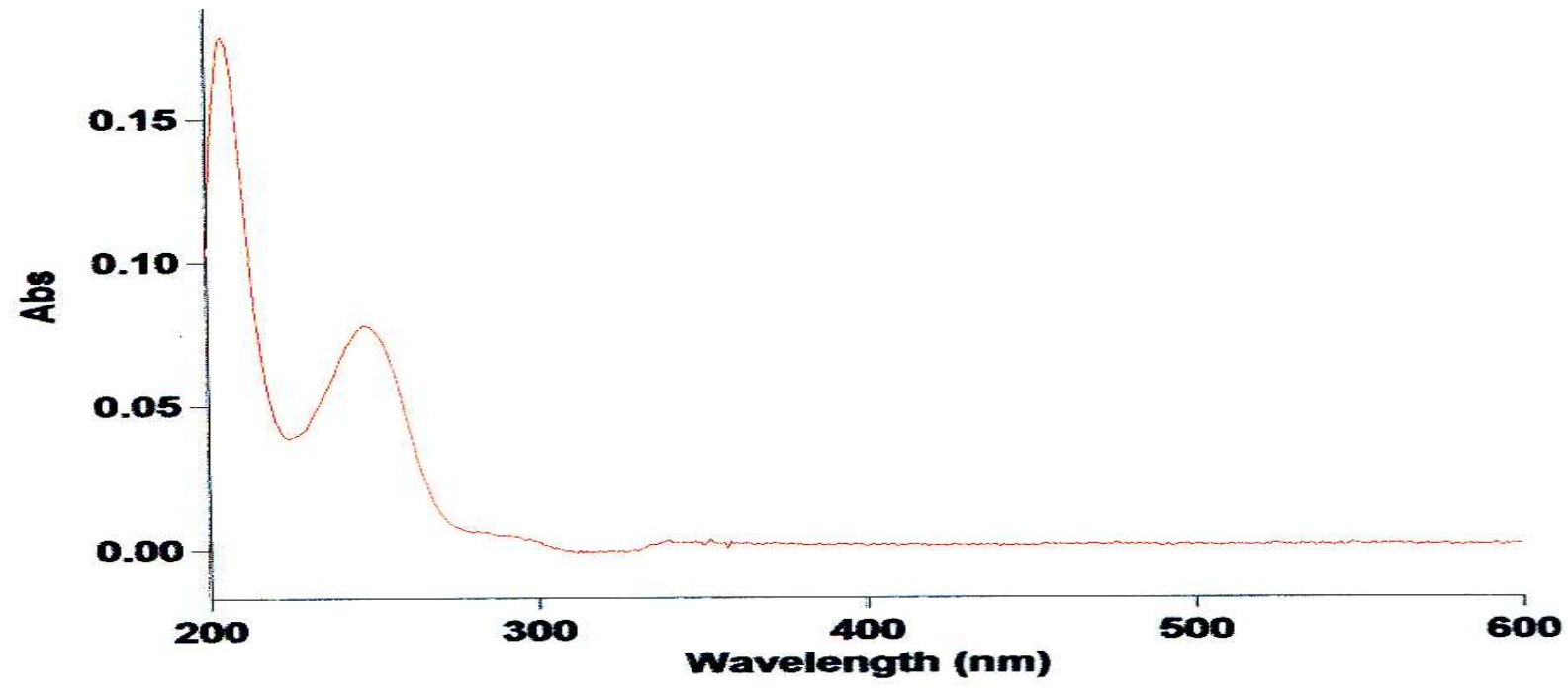

Fig. 49. UV $\left(\mathrm{CH}_{3} \mathrm{OH}\right)$ spectrum of 6

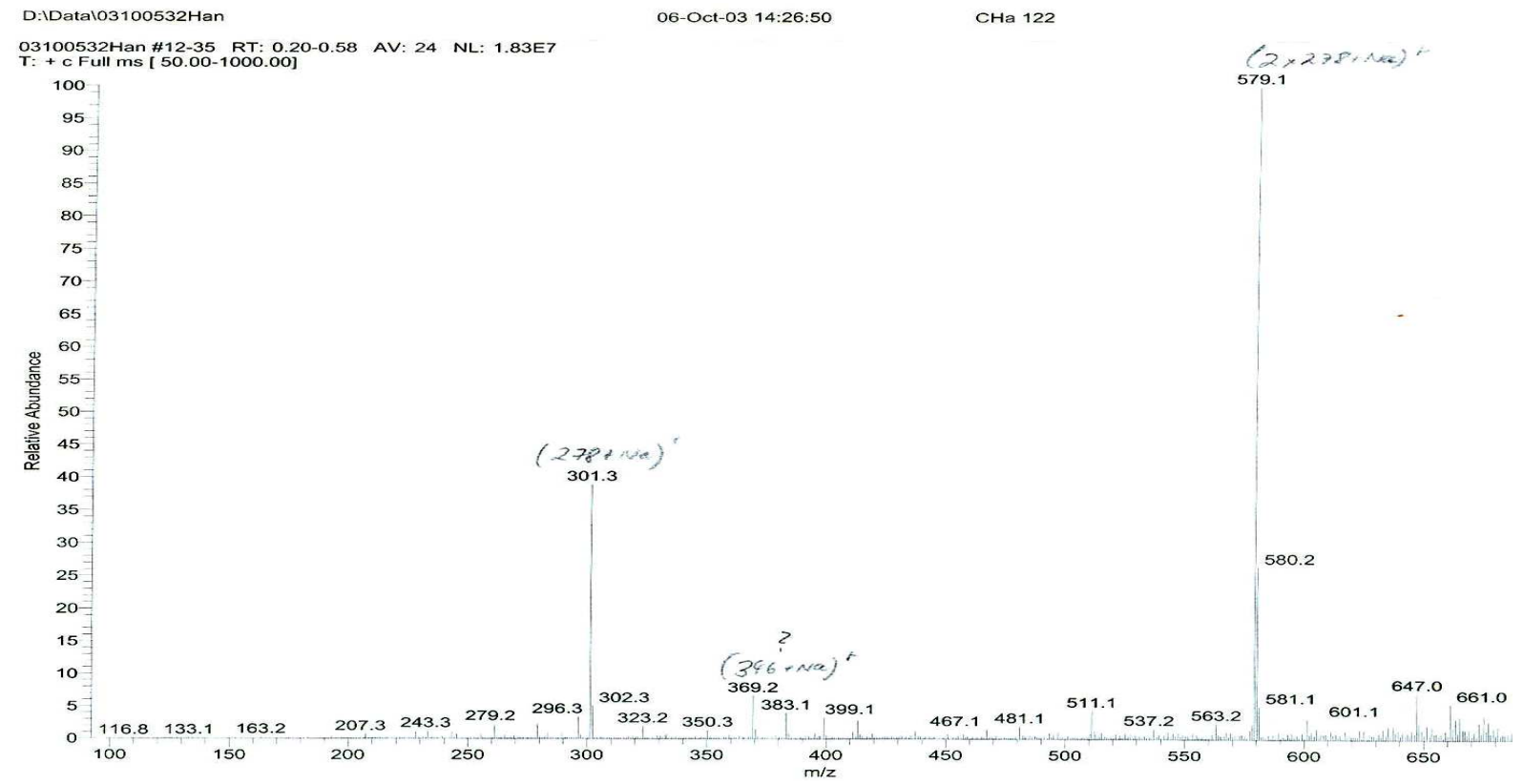

Fig. 50. ESI-MS spectrum of 7 


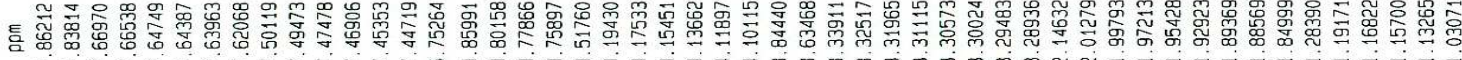

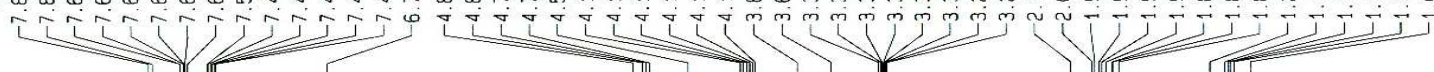

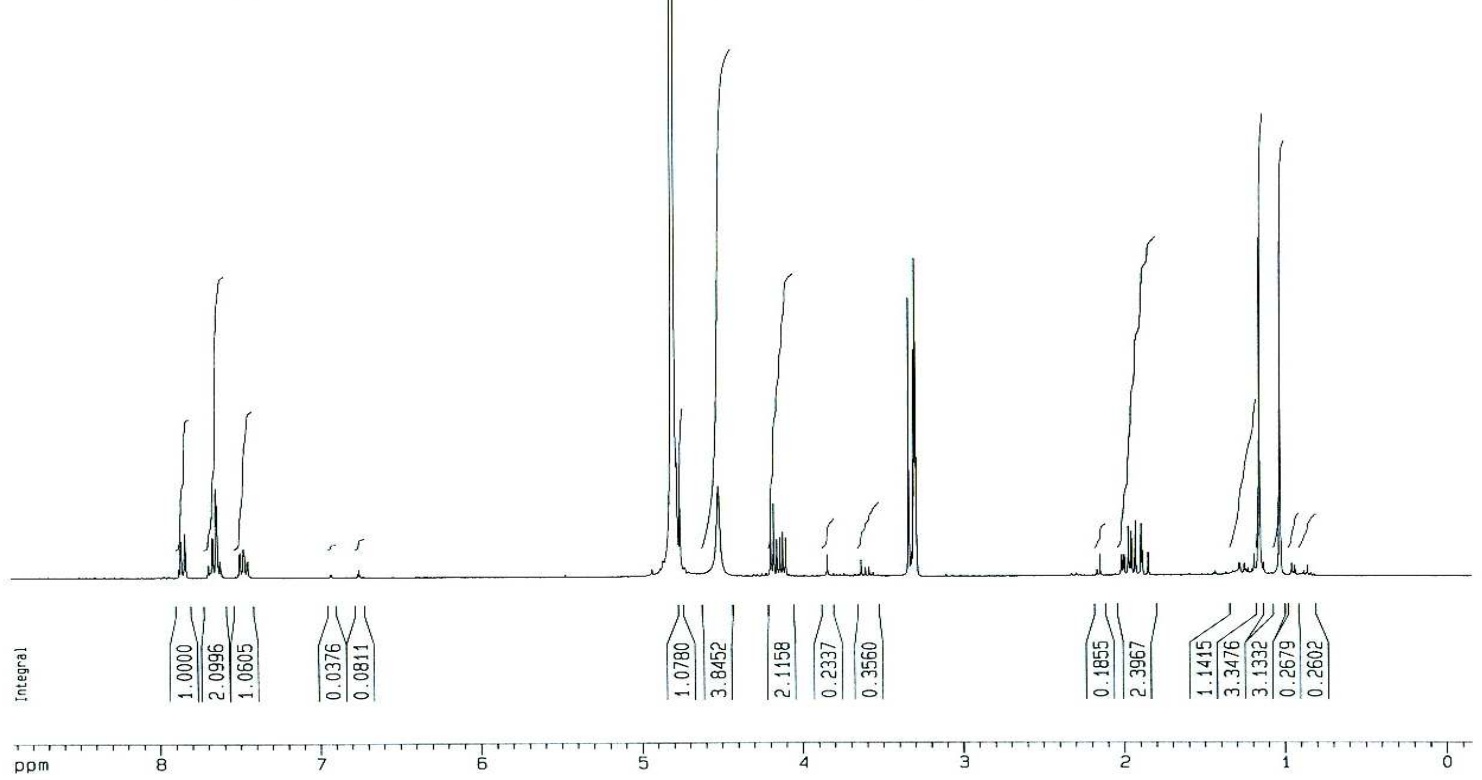

Fig. 51. ${ }^{1} \mathrm{H}-\mathrm{NMR}$ spectrum of 7

CHA $122 / C D 300 / H a$

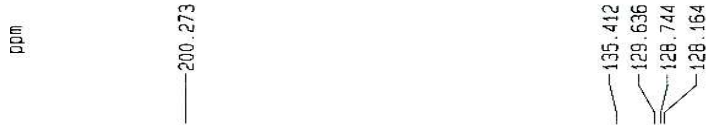

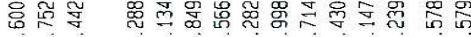

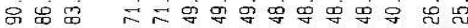

11 Y wity

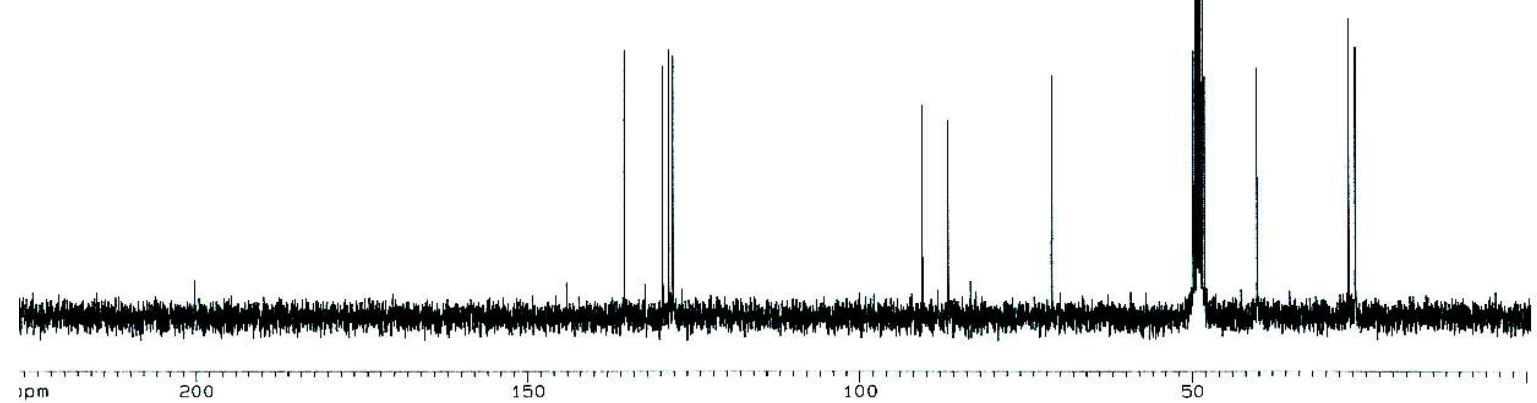

Fig. $52 .{ }^{13} \mathrm{C}-\mathrm{NMR}$ spectrum of 7 
Tर

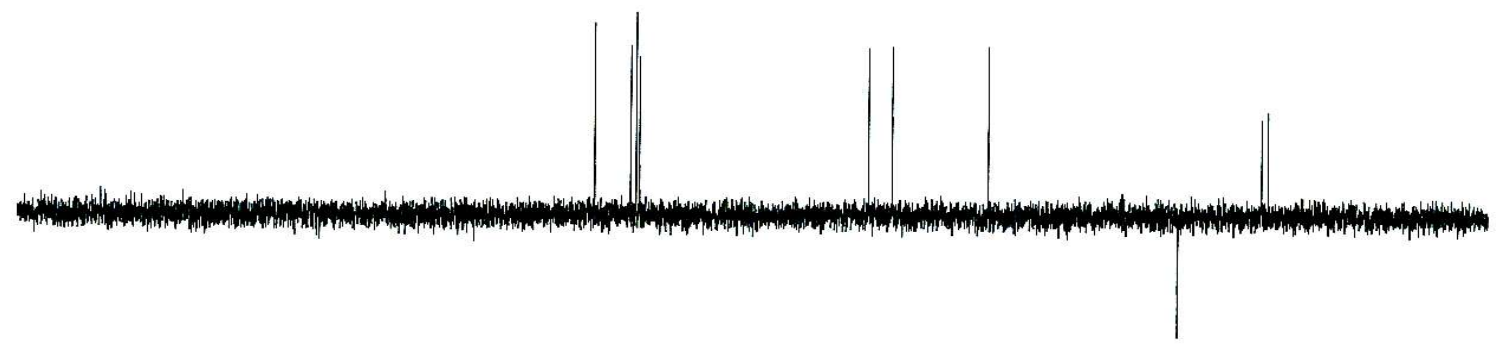

ppm

Fig. 53. DEPT spectrum of 7

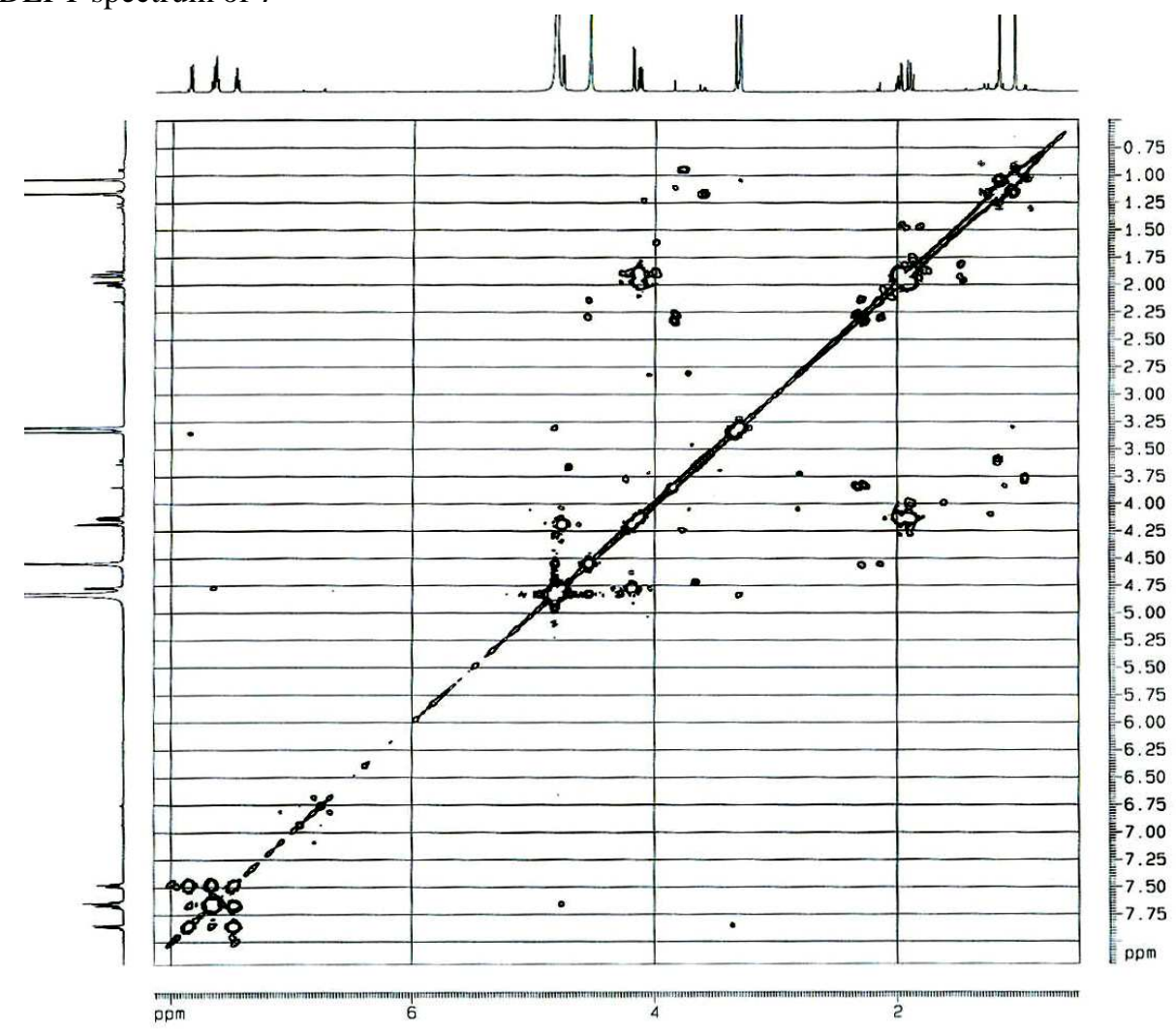

Fig. 54. COSY spectrum of 7 


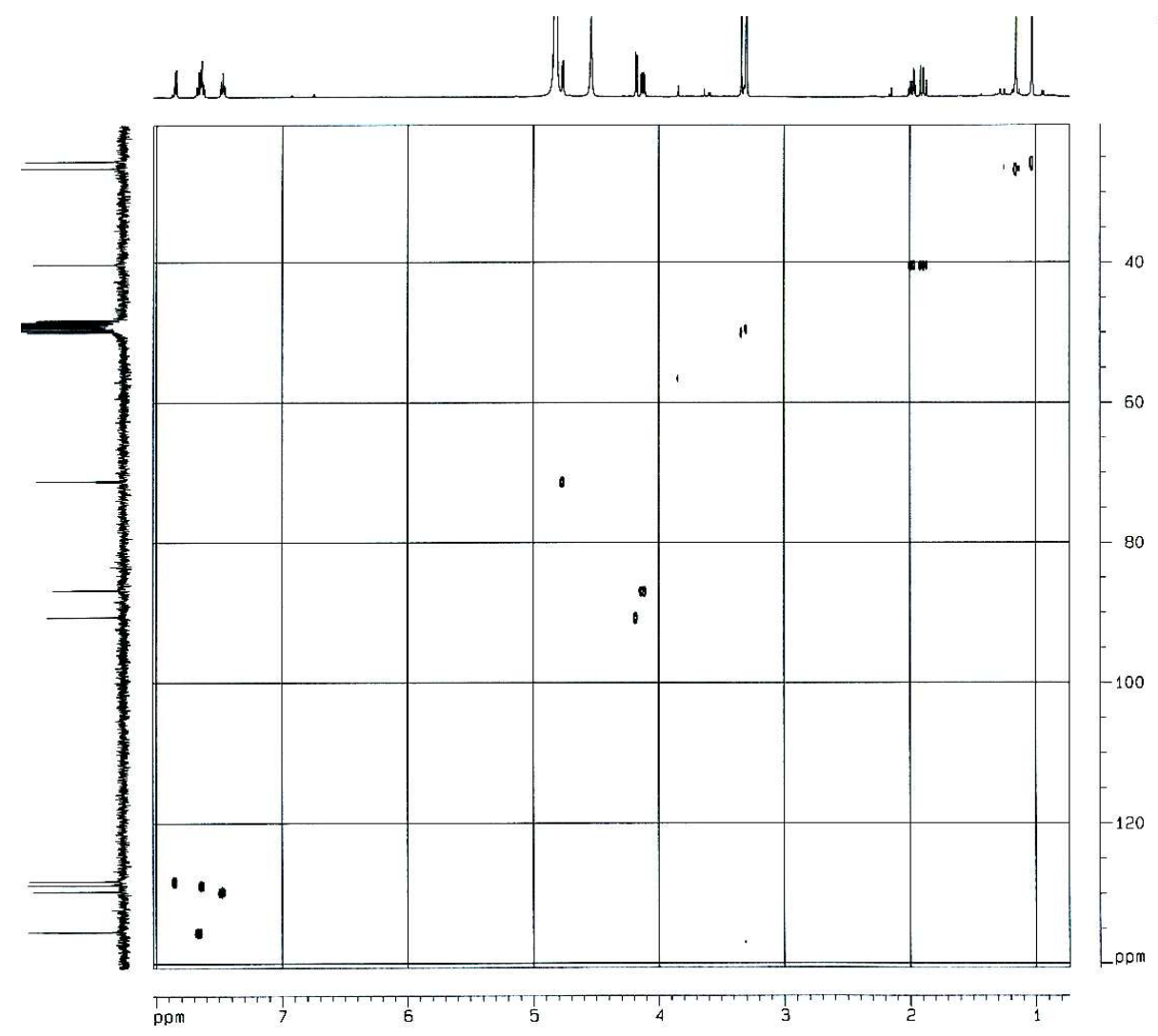

Fig. 55. HMQC spectrum of 7

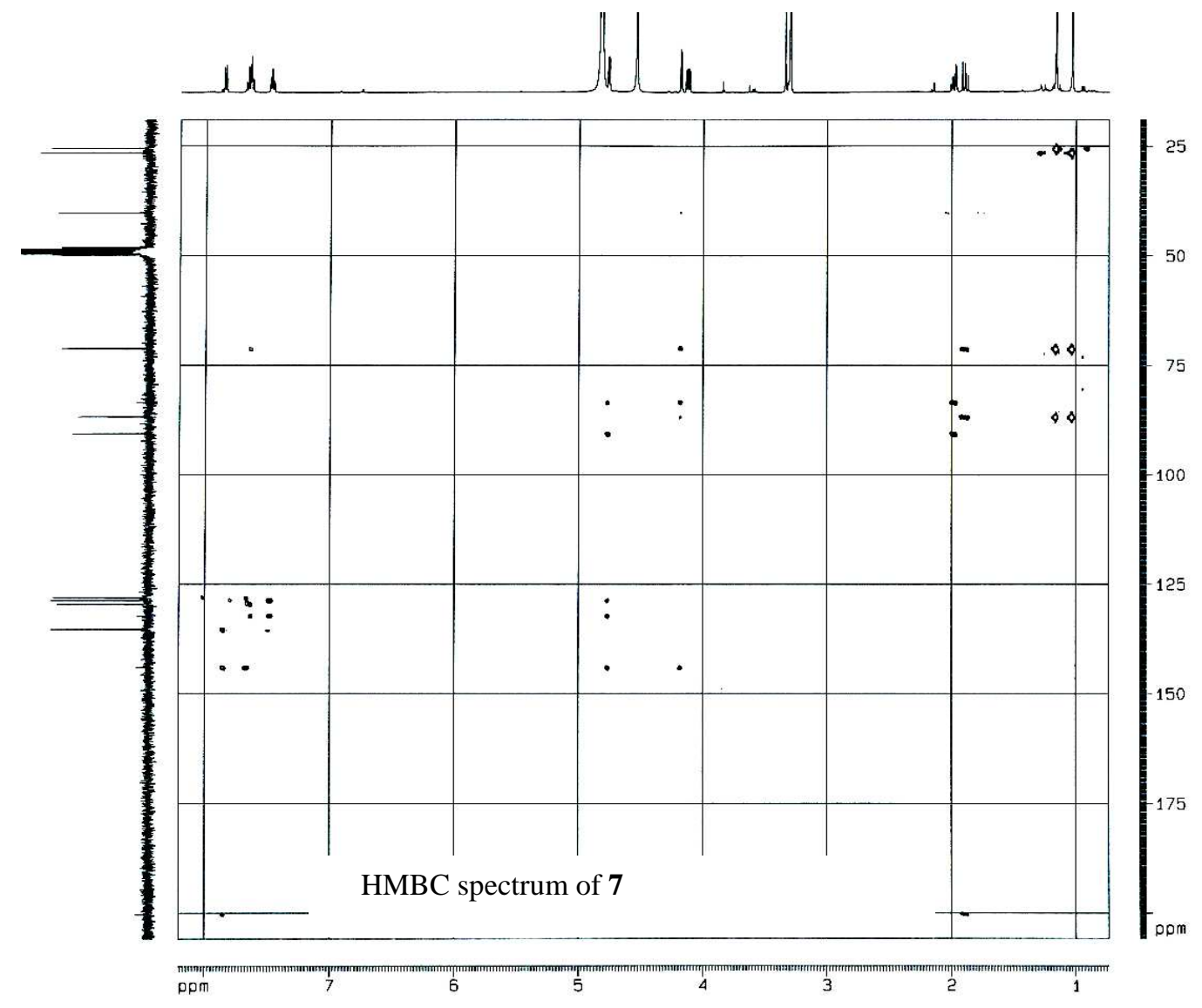

Fig. 56. HMBC spectrum of 7 


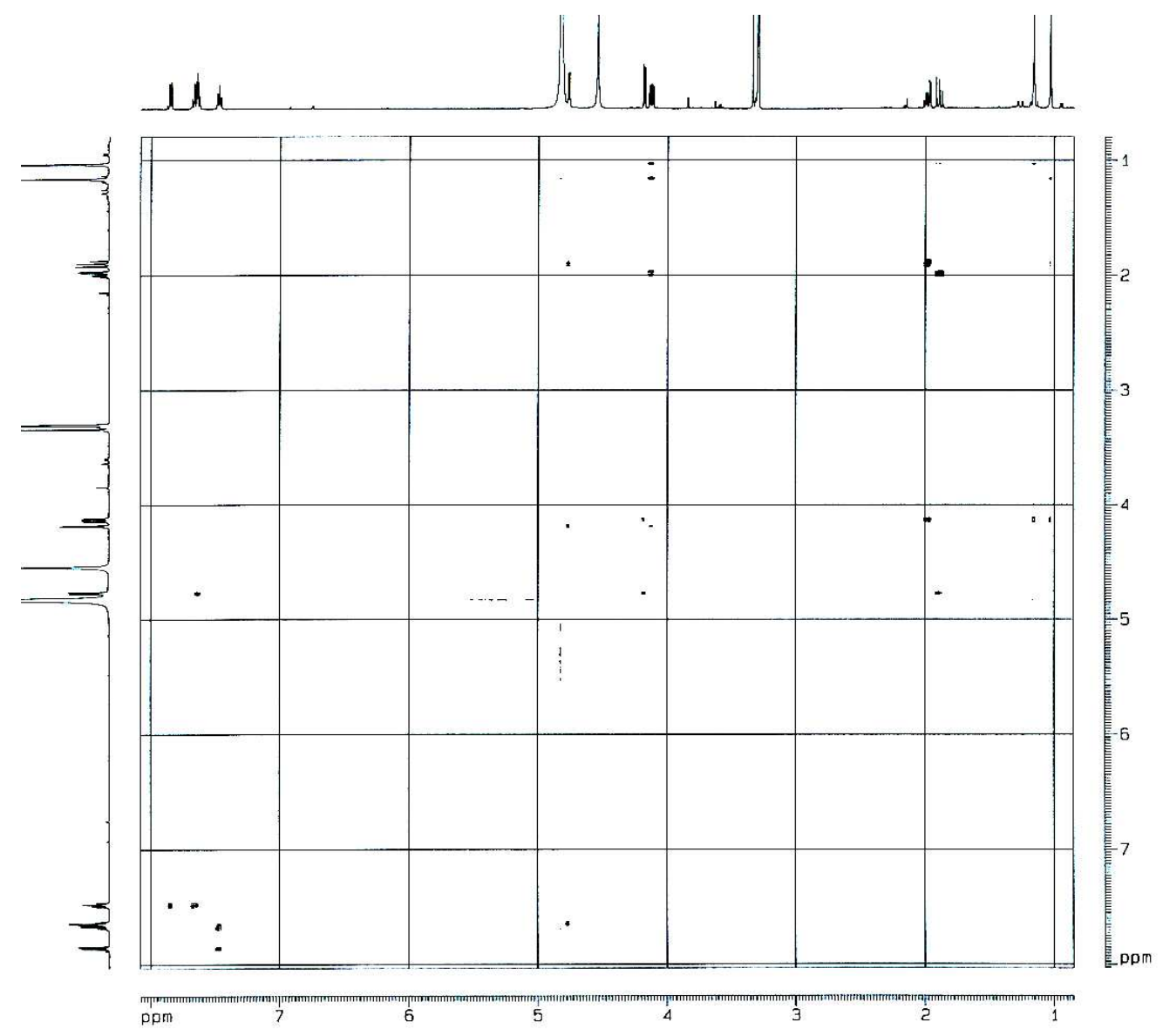

Fig. 57. NOESY spectrum of 7

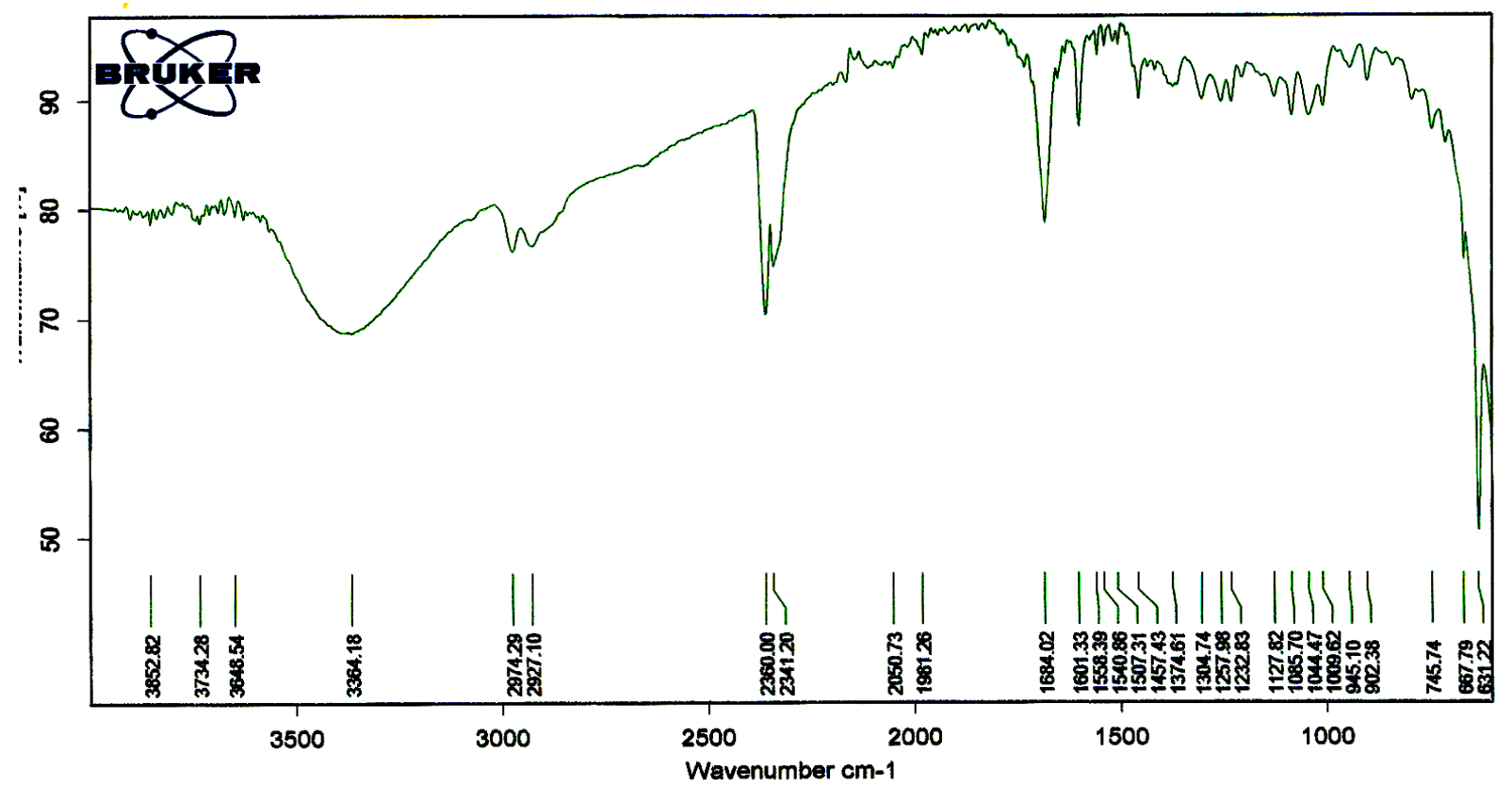

Fig. 58. IR spectrum of 7 


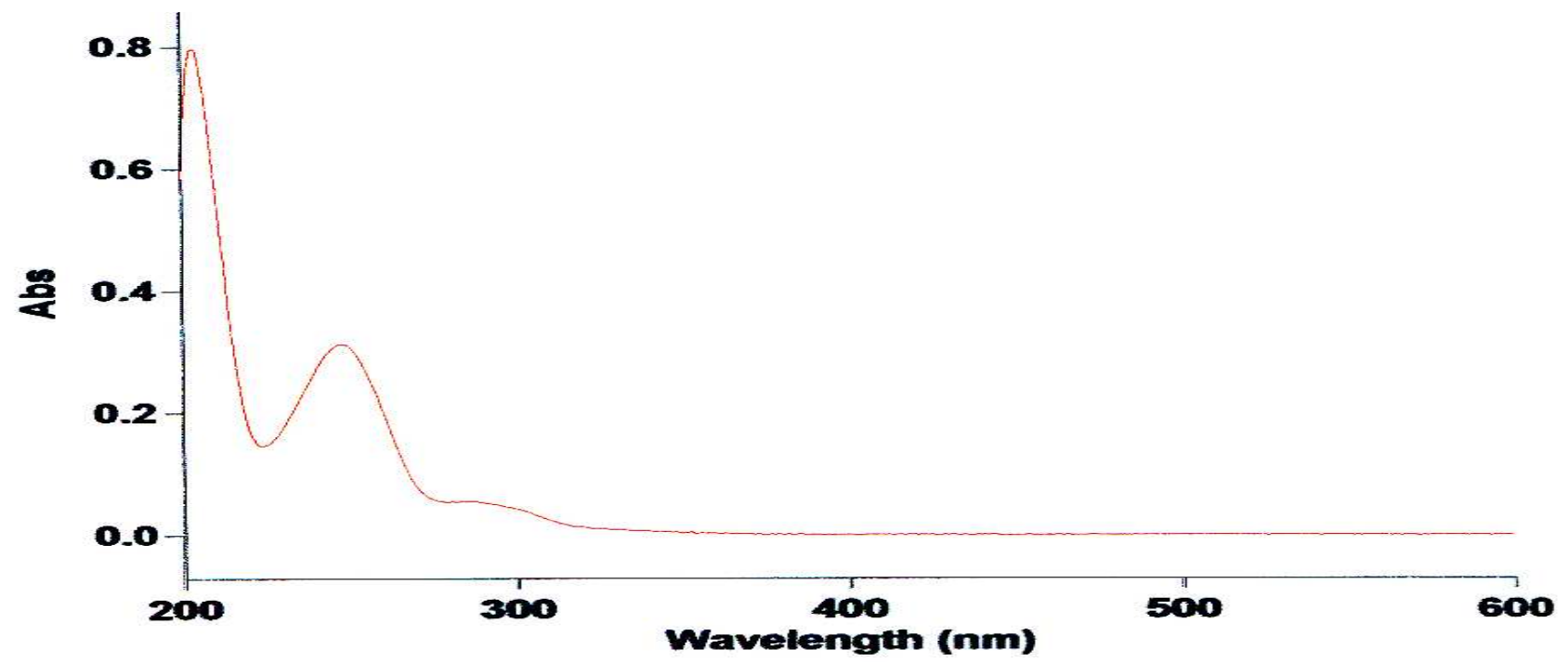

Fig. 59. UV $\left(\mathrm{CH}_{3} \mathrm{OH}\right)$ spectrum of 7 